Prepared in cooperation with the U.S. Navy

\title{
Black Abalone Surveys at Naval Base Ventura County, San Nicolas Island, California: 2020, Annual Report
}

Open-File Report 2021-1023

U.S. Department of the Interior

U.S. Geological Survey 
Cover Photo: Crashing wave, west end of San Nicolas Island, California. Photograph taken by Esther Kenner, volunteer, January 18, 2018. 


\section{Black Abalone Surveys at Naval Base Ventura County, San Nicolas Island, California: 2020, Annual Report}

By Michael C. Kenner

Prepared in cooperation with the U.S. Navy

Open-File Report 2021-1023 


\section{U.S. Geological Survey, Reston, Virginia: 2021}

For more information on the USGS - the Federal source for science about the Earth, its natural and living resources, natural hazards, and the environment—visit https://www.usgs.gov or call 1-888-ASK-USGS.

For an overview of USGS information products, including maps, imagery, and publications, visit https://store.usgs.gov/.

Any use of trade, firm, or product names is for descriptive purposes only and does not imply endorsement by the U.S. Government.

Although this information product, for the most part, is in the public domain, it also may contain copyrighted materials as noted in the text. Permission to reproduce copyrighted items must be secured from the copyright owner.

Suggested citation:

Kenner, M.C., 2021, Black abalone surveys at Naval Base Ventura County, San Nicolas Island, California—2020, annual report: U.S. Geological Survey Open-File Report 2021-1023, 33 p., https://doi.org/10.3133/ofr20211023.

ISSN 2331-1258 (online) 


\section{Acknowledgments}

Most of the work presented in this report is that of Glenn VanBlaricom, U.S. Geological Survey, retired, who passed away in December 2020. Aside from his status as an abalone researcher, Glenn was an avid naturalist and was best known for his studies of kelp forest ecology, cetaceans, and sea otters. He installed the black abalone sites at San Nicolas Island in 1980, led the monitoring of them for 27 years, and continued on as a volunteer after his retirement. Over the years, he introduced countless students to the intertidal environment and gave them the unique opportunity to work in the field alongside experts from other disciplines. Without his vision, hard work, and dedication there would be no project. His expertise, good humor, and enthusiasm made him a pleasure to work with. He will be missed.

Additionally, I would like to thank the U.S. Navy for funding and facilitating this research project. My field assistants in 2020 were Ken Collins, Joey Curti, Shannon Myers, Melissa Neuman, Glenn VanBlaricom,

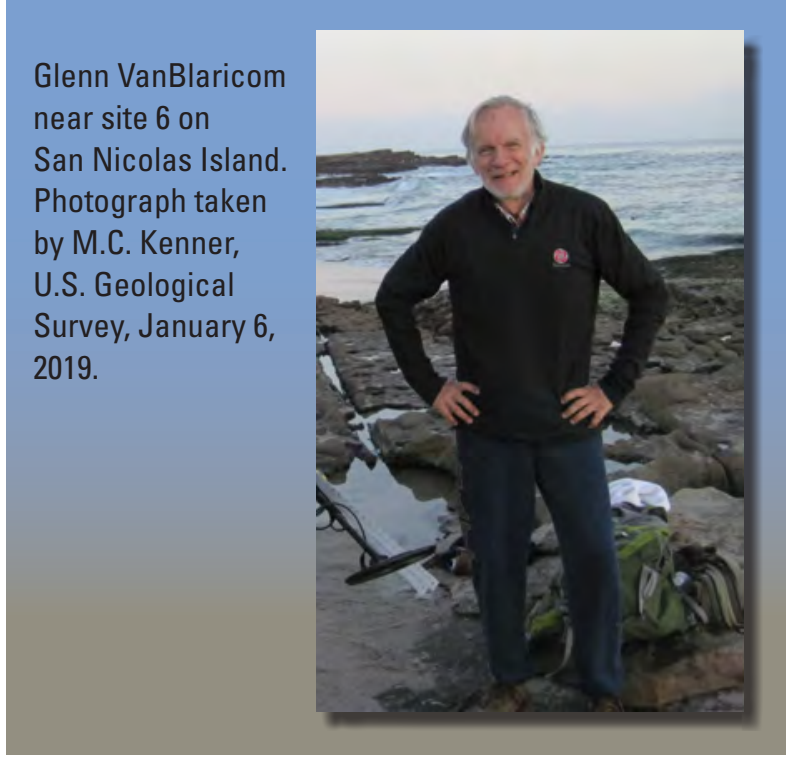

and Susan Wang. Thank you to Julie Yee for help with $\mathrm{R}$ and generalized additive model functions. The manuscript was much improved by comments from Steve Whitaker and Susan Wang. Thank you also to Esther Kenner who again played a key role in planning, logistics, and moral support. 



\section{Contents}

Acknowledgments ……...................................................................................................................

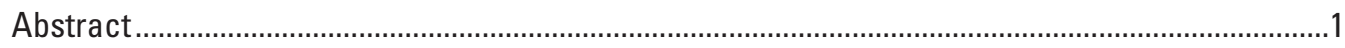

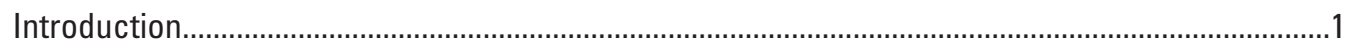

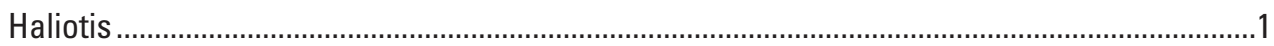

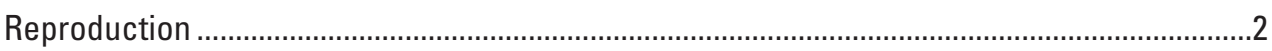

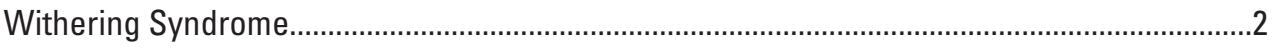

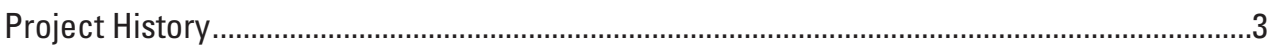

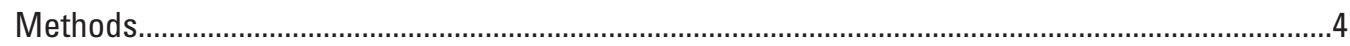

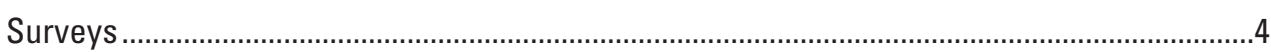

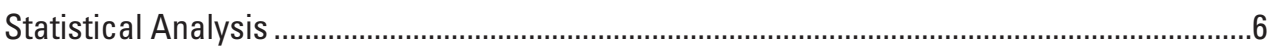

Sites

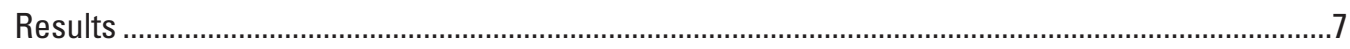

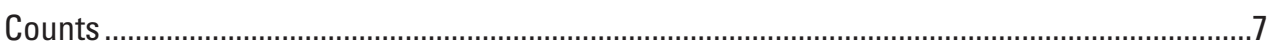

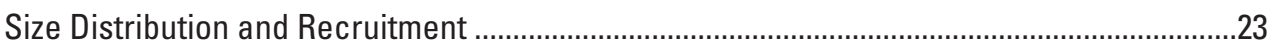

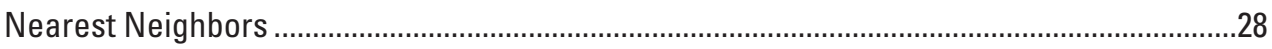

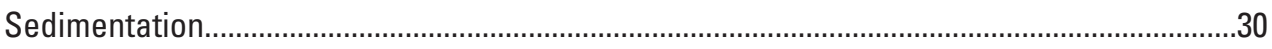

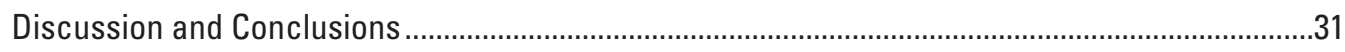

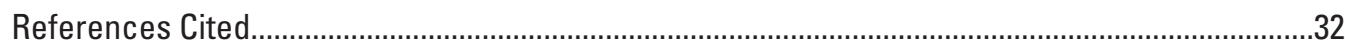

\section{Figures}

1. Map showing black abalone monitoring sites around San Nicolas Island, California .....3

2. Image showing major events during the black abalone sampling history, San Nicolas Island, California ....................................................................................................

3. Photographs showing how shell length is measured to the nearest millimeter by using dividers and a ruler, San Nicolas Island, California .............................................

4. Graph showing total black abalone counts, generalized additive model nonlinear regression, and 95-percent confidence band, San Nicolas Island, California, 2001-20.

5. Graphs showing black abalone count at each site and island total at San Nicolas Island, California, plotted on log scale 2001-20.

6. Graph showing black abalone count at each of the nine San Nicolas Island, California, sites during the course of the study and the 2001-20 recovery phase following the withering syndrome outbreak

7. Graph showing contribution to total black abalone counts for 2001-20, San Nicolas Island, California

8. Graphs showing cycle 28 , cycle 29 , and cycle 30 distribution of black abalone along transects at site 1, San Nicolas Island, California, 2018-20...

9. Graphs showing cycle 28 , cycle 29 , and cycle 30 distribution of black abalone along transects at site 2, San Nicolas Island, California, 2018-20..

10. Graphs showing cycle 28 , cycle 29 , and cycle 30 distribution of black abalone along transects at site 3, San Nicolas Island, California, 2018-20.

11. Graphs showing cycle 28 , cycle 29 , and cycle 30 distribution of black abalone along transects at site 4, San Nicolas Island, California, 2018-20. 
12. Graphs showing cycle 28 , cycle 29 , and cycle 30 distribution of black abalone along transects at site 5, San Nicolas Island, California, 2018-20

13. Graphs showing cycle 28 , cycle 29 , and cycle 30 distribution of black abalone along transects at site 6, San Nicolas Island, California, 2018-20.

14. Graphs showing cycle 28 , cycle 29 , and cycle 30 distribution of black abalone along transects at site 7, San Nicolas Island, California, 2018-20.

15. Graphs showing cycle 28 , cycle 29 , and cycle 30 distribution of black abalone along transects at site 8, San Nicolas Island, California, 2018-20.

16. Graphs showing cycle 28 , cycle 29 , and cycle 30 distribution of black abalone along transects at site 9, San Nicolas Island, California, 2018-20.

17. Photograph showing two black abalone recruits at site 5, January 2018, San Nicolas Island, California

18. Graphs showing whole island size distributions of black abalone for 1988 and 2001-20, San Nicolas Island, California

19. Graph showing size distribution of each site in 2019 and 2020, San Nicolas Island, California .25

20. Graphs showing recruitment pulse as observed in the size distribution measured in 2016-20 at site 8, transects 1 and 2, San Nicolas Island, California

21. Graph showing mean nearest neighbor distance in 2005-20 and percentage of sample within 10 centimeters $(\mathrm{cm})$ and within $100 \mathrm{~cm}$ of neighbor, San Nicolas Island, California....

22. Graph showing nearest neighbor distance bins by site for 2020, San Nicolas Island, California

23. Graph showing average sand cover on selected transects for 2001-20, San Nicolas Island, California

24. Graph showing abalone counts and sand cover by quadrat for site 7, transect 4 in cycle 29 and cycle 30, San Nicolas Island, California.

\section{Tables}

1. Numbers of transects and their lengths and areas at each site, San Nicolas Island, California

2. Period and per annum percentage changes in mean black abalone counts during given periods calculated from generalized additive model analysis, San Nicolas Island, California, 2001-20

3. Counts for each sampling cycle, San Nicolas Island, California, 1981-2020

4. Distribution among microhabitats by site and transect, San Nicolas Island, California, 2020

5. Number and percentage of measured abalone at each site that were recruits for cycles 11-30 and total recruits for each cycle, San Nicolas Island, California .........26

6. Total recruits for cycles 15-30 by nearest neighbor distance bin, San Nicolas Island, California 


\section{Conversion Factors}

International System of Units to U.S. customary units

\begin{tabular}{lll}
\hline \multicolumn{1}{c}{ Multiply } & \multicolumn{1}{c}{ By } & \multicolumn{1}{c}{ To obtain } \\
\hline \multicolumn{1}{c}{ Length } \\
\hline centimeter $(\mathrm{cm})$ & 0.3937 & inch (in.) \\
millimeter $(\mathrm{mm})$ & 0.03937 & inch (in.) \\
meter $(\mathrm{m})$ & 3.281 & foot (ft) \\
meter $(\mathrm{m})$ & 1.094 & yard (yd) \\
\hline \multicolumn{3}{c}{ Area } \\
\hline square meter $\left(\mathrm{m}^{2}\right)$ & 0.0002471 & acre \\
\hline
\end{tabular}

\section{Abbreviations}

$\begin{array}{ll}\text { CaXc } & \text { Candidatus Xenohaliotis californiensis } \\ \text { GAM } & \text { generalized additive model } \\ \text { INRMP } & \text { Integrated Natural Resources Management Plan } \\ \text { NMFS } & \text { National Marine Fisheries Service } \\ \text { SNI } & \text { San Nicolas Island } \\ \text { WS } & \text { withering syndrome }\end{array}$





\title{
Black Abalone Surveys at Naval Base Ventura County, San Nicolas Island, California: 2020, Annual Report
}

\author{
By Michael C. Kenner
}

\section{Abstract}

The U.S. Geological Survey monitors a suite of intertidal black abalone sites at San Nicolas Island, California, in cooperation with the U.S. Navy, which owns the island. The nine rocky intertidal sites were established in 1980 to study the potential impact of translocated sea otters on the intertidal black abalone population at the island. The sites were monitored from 1981 to 1997 , usually annually or biennially. Monitoring resumed in 2001 and has been completed annually since then. At the time of this report, the work is conducted by the Western Ecological Research Center's Santa Cruz Field Station, Santa Cruz, California. The study sites became particularly important, from a management perspective, after a virulent disease decimated black abalone populations throughout southern California beginning in the mid-1980s. The disease, withering syndrome, was first observed on San Nicolas Island in 1992 and during the next few years, it reduced the population there by more than 99 percent. The species was subsequently listed as endangered under the Endangered Species Act in 2009.

The subject of this report is the 2020 monitoring cycle of the sites and how the current status fits into the long-term data at San Nicolas Island. Since 2001, the monitored population has increased twelvefold to approximately 9.6 percent of the pre-disease level. This increase has resulted from generally higher levels of recruitment than seen in the first two decades of monitoring, punctuated by a few unexplained high recruitment events. Most of the population growth has been at two of the nine sites (sites 7 and 8). This pattern continued in 2020, but with increasing numbers at all sites and the highest number of abalone counted and measured island-wide since 1993. Recruitment rates have fallen since a peak in 2017 , but 2020 continued to show moderate levels of additional recruitment. The distance between adjacent black abalone has decreased substantially since it was first consistently measured in 2005 , potentially indicating that the abalone are close enough to one another to reproduce successfully. Sand burial can have devastating localized consequences to black abalone, but there is evidence suggesting that they may be able to escape periodic sand inundation if suitable refugia exist. These data suggest that monitoring can inform adaptive management of the resource by base resource managers.

\section{Introduction}

\section{Haliotis}

The black abalone (Haliotis cracherodii) is one of seven species of Haliotis endemic to the west coast of North America and found in California waters (California Department of Fish and Game, 2004). The other Haliotis species that are native to California are the green abalone $(H$. fulgens), the red abalone (H. rufescens), the pink abalone (H. corrugata), the white abalone (H. sorenseni), the pinto abalone (H. kamtschatkana) and the flat abalone ( $H$. walallensis). At the time of this report, there are 55 species and several subspecies of Haliotis recognized world-wide by the Integrated Taxonomic Information System (ITIS, www.ITIS.gov) and World Registry of Marine Species (WoRMS, www.marinespecies.org). The genus consists of prosobranch gastropods typified by ear-shaped shells that are pierced by several small spiracle holes. The shells are prized for their iridescent pearly appearance and have been used in jewelry, decorations, and even tools for millennia (Morris and others, 1980; Rick and others, 2002). The flesh of the large muscular foot also is considered to be a delicacy, and historically, abalone meat has commanded high prices. Though varying considerably in size, several of the California species are large for gastropods. Of the seven species, six were extensively fished, and though black abalone are considered inferior because of their tougher flesh, they sustained a recreational and commercial fishery until the 1990s. The commercial take for this species peaked in 1973 at a little under 2-million pounds (California Department of Fish and Game, 2004).

The black abalone is found on rocky shores from the high intertidal to a depth of approximately 6 meters (m), shallower than the other local species of the genus. Its range extends from Pt. Arena, California, to Isla de Cedros, Baja California Sur, Mexico, but it is most abundant from central California southward (VanBlaricom and others, 2009). 
Smaller black abalone feed on diatom films and coralline algae, whereas larger individuals are thought to feed mainly on kelp wrack (VanBlaricom and Kenner, 2020). The species can attain a shell length of up to 20 centimeters $(\mathrm{cm})$. In addition to humans, natural predators of the black abalone include octopuses (Octopus spp.), sea stars (especially Pisaster ochraceus), cabezon (Scorpaenichthys marmoratus), and sea otters (Enhydra lutris; Morris and others, 1980).

The species is relatively sedentary, and some large specimens can go years without apparent movement. However, some of the few studies that have addressed movement in black abalone have found that smaller individuals are more mobile and capable of movement on the order of several centimeters to a few meters in a day (VanBlaricom and others, 2009).

\section{Reproduction}

Like many marine invertebrates, black abalone reproduce by broadcast spawning; a reproductive strategy in which mature male and female individuals release large numbers of gametes into the environment with no mutual physical contact necessary. Successful fertilization likely requires both temporal synchrony and relatively close spatial proximity. Although several studies have concluded that black abalone populations spawn in late summer (Boolootian and others, 1962; Leighton and Boolootian, 1963; Webber and Giese, 1969), the actual trigger for spawning is unknown. In fact, unlike several other species of Haliotis, spawning of $H$. cracherodii in the laboratory has been met with limited success. Because the concentration of gametes in seawater is inversely related to the cube of the distance from their source, the proximity of spawning individuals is important to successful fertilization. Black abalone, as noted in the previous section, are somewhat sedentary and do not aggregate to spawn. There are many confounding factors to consider when attempting to calculate critical reproductive distance in intertidal organisms such as turbulence, channeling of water through crevices, and residency time in pools. It is likely though, that inter-abalone distances greater than a few meters result in reduced reproductive success compared with shorter distances (VanBlaricom and others, 2009), and average adult densities below 0.34 square meters $\left(\mathrm{m}^{2}\right)$ were found to lead to recruitment failure in some populations (Neuman and others, 2010). Abalone produce non-feeding larvae with a relatively short larval planktonic period. For this reason, bolstered by genetic evidence, it is thought that black abalone likely disperse relatively short distances (Chambers and others, 2006).

\section{Withering Syndrome}

Withering syndrome (WS) is a disease that affects many species of Haliotis and results in atrophy of the "foot" and a diminished ability to cling to hard substrate. Animals showing signs of WS exhibit body shrinkage as the disease progresses due to a combination of reduced food intake and changes in the structure of the digestive gland. The progressive degeneration eventually leads to death. The causative agent has been identified as a Rickettsiales-like prokaryotic organism (often referred to in the literature as "RLO"), specifically Candidatus Xenohaliotis californiensis (CaXc; Friedman and others, 2002). The disease was first observed in black abalone on the California Channel Islands. Beginning at Santa Cruz Island in 1985, it spread through the Channel Islands during the next few years, arriving at San Nicolas Island (SNI) in 1992 (Lafferty and Kuris, 1993; VanBlaricom and others, 1993). In black abalone populations afflicted with the disease, there is typically a mortality rate of at least 90 percent. Most southern California black abalone populations have been devastated by the disease. It has since moved into central California populations, where it has caused significant levels of mortality (Miner and others, 2006). Although $\mathrm{CaXc}$ has been found in coastal marine waters in central California, thus far black abalone populations north of San Luis Obispo County have not shown signs of the disease (National Marine Fisheries Service, 2020). Elevated water temperatures may accelerate disease transmission and mortality rates (Raimondi and others, 2002). Recent work has suggested that there is now genetic resistance to the WS infection in some black abalone populations on SNI. In addition, a viral bacteria-phage could lend some protection by infecting $\mathrm{CaXc}$ (Friedman and others, 2014). Still, it is too early to know how effective these factors will be in protecting wild populations.

The National Marine Fisheries Service (NMFS) listed H. cracherodii as an endangered species in January 2009 to address concerns about the serial near-extinction of populations in southern California and Mexico, the continued movement of WS northward, and potential recruitment failures (74 FR 9, January 14, 2009).

In their critical habitat designation for the black abalone, the NMFS excluded SNI due to revisions in the Navy's Integrated Natural Resource Management Plan (INRMP) that provide benefits to black abalone (76 FR 208, October 27, 2011). One of the management strategies for marine invertebrates set forth in the INRMP was to "Promote and discuss current long-term monitoring of black abalone populations established in the late 1970s (VanBlaricom, 1993) and ensure that survey information on existing populations and trends are made available to the general scientific community" (U.S. Navy, 2015). 


\section{Project History}

The black abalone monitoring sites were established on SNI in 1980 (fig. 1) and first sampled in 1981 by Glenn VanBlaricom, then of the U.S. Fish and Wildlife Service. From 1981 to 1997, with a few exceptions, all sites were sampled during 10 cycles that each took 1 or 2 years to complete. Missed samples were as follows: transect 4 of site 7 was not completed in cycle 1 , and transect 6 of site 1 and sites 3 and 8 were not sampled in cycle 2. Sampling was suspended during 1998-2000 due to an interruption in funding but resumed in 2001 .

During the 1980s and 1990s, size sampling (measuring shell length) was conducted opportunistically, but several size samples of 100 or more individuals were taken between 1983 and 1993, resulting in nearly 3,400 measurements taken during two to four different cycles at each site. On randomly selected transects at each site, and beginning at a quadrat and direction that also were randomly chosen, all reachable abalone were measured until the sample size was reached.

Since its resumption in 2001, sampling of all sites was completed every year, and all accessible abalone were measured (up to 200 per site). The nearest neighbor distances for black abalone were measured consistently beginning in 2005. All sampling trips through 2017 were led by Glenn VanBlaricom. Monitoring cycles during 2018-2020 were supported by the U.S. Navy and led by the author. The 2020 field season represented the 30th cycle of sampling the sites since they were established. A timeline of significant events is shown in figure 2.

The original impetus for monitoring black abalone was the planned reintroduction of the southern sea otter (Enhydra lutris nereis), a top marine carnivore that feeds almost exclusively on shellfish and that had been absent from the system for nearly a century due to overhunting. Between 1987 and 1990, 139 sea otters were translocated to SNI from the central California coast population (Rathbun and others, 2000). Sea otters, at northern locations, have significantly affected subtidal red abalone populations, driving them below commercially viable levels (Watson, 2000). The potential impact of sea otter predation on intertidal black abalone populations was uncertain, however, because they do not regularly use the intertidal zone for foraging (VanBlaricom, 1993).

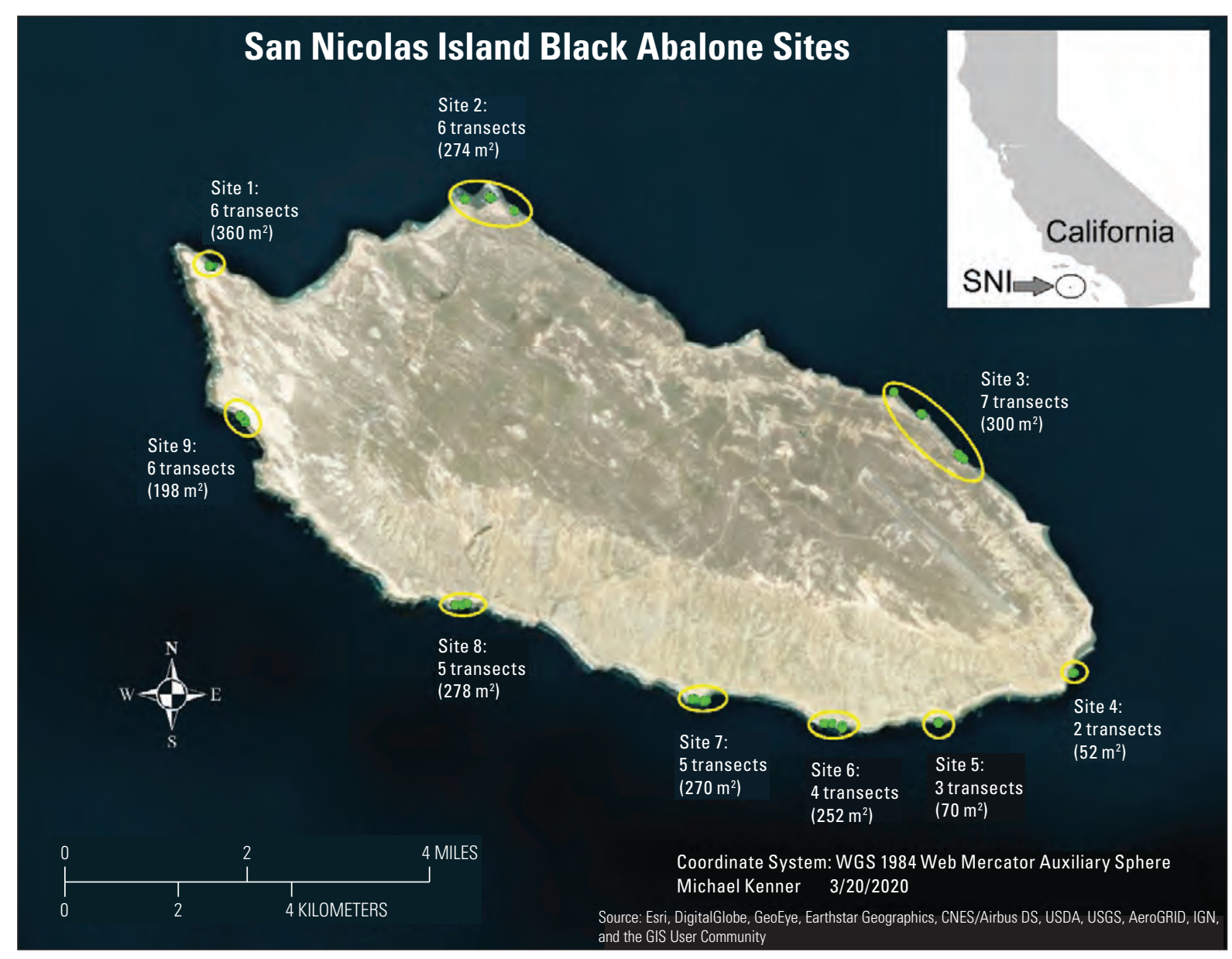

Figure 1. Black abalone monitoring sites around San Nicolas Island, California. 


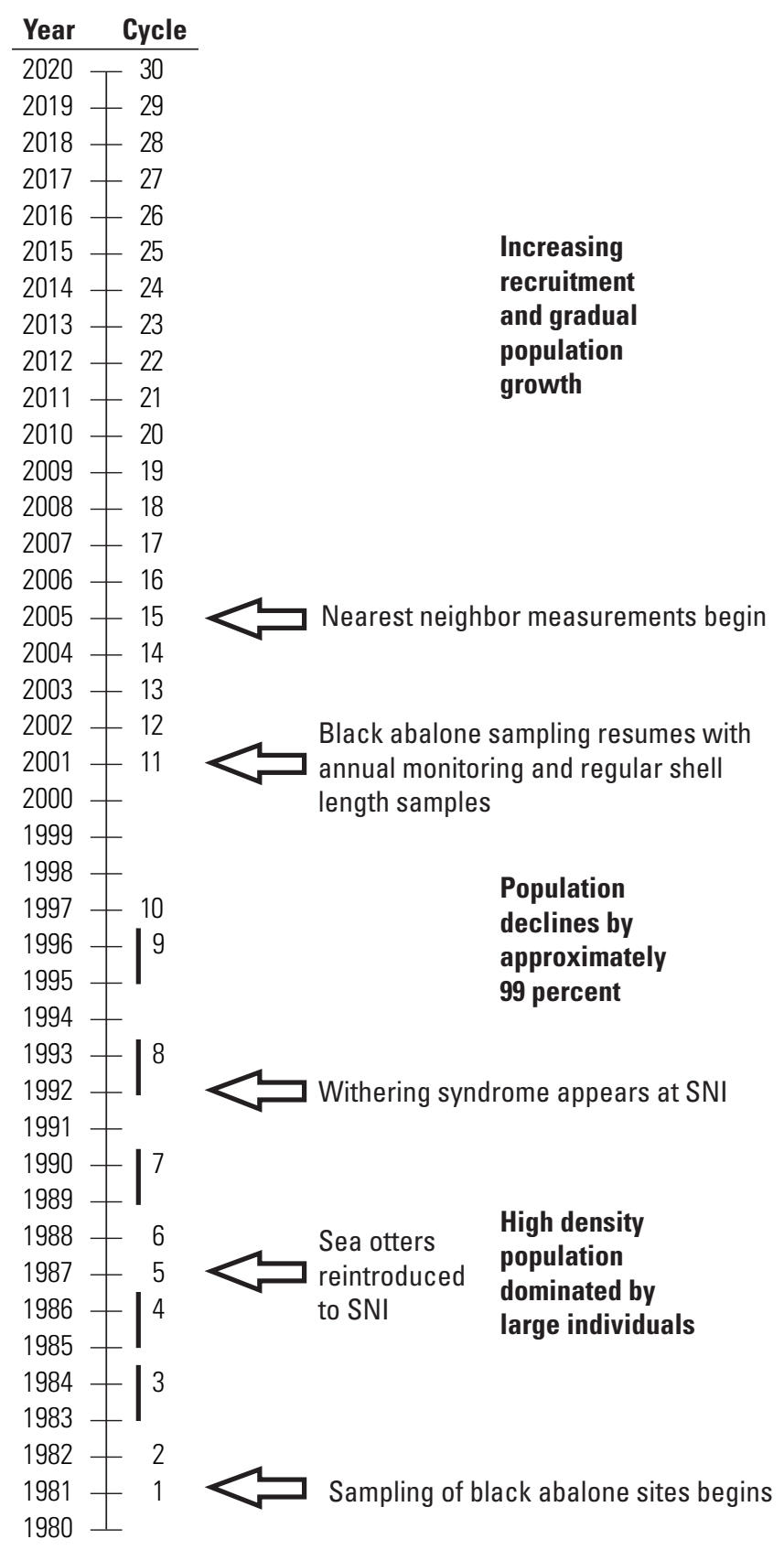

Figure 2. Timeline of major events during the black abalone sampling history, San Nicolas Island, California.

During the first 10 years of monitoring, black abalone were very densely aggregated at the sites, with mean densities ranging from about 4 to 28 per $\mathrm{m}^{2}$ and with some $1-\mathrm{m}^{2}$ quadrats having more than 100 abalone stacked several deep. To what extent these densities were a natural or normal baseline, is arguable. Pressure from sea otter foraging was removed because of the otter population's extirpation by fur hunters in the 19th century. Even human harvest, that had been part of the system for millennia, was greatly reduced following the removal of indigenous people from SNI in 1835. Also, the establishment of active military control of the island in 1942 likely reduced access for most commercial and sport take from then on.

Ironically, disease, rather than sea otter predation, caused the black abalone populations at SNI to decline. From the time WS appeared at SNI in 1992 until 2001, when regular annual sampling resumed, the population at these nine monitoring sites was reduced by more than 99 percent. U.S. Geological Survey intertidal monitoring sites on SNI, that use fixed quadrats not specifically targeting abalone, recorded a decline of similar magnitude during the same period (M.C. Kenner, unpub. data, 2020).

\section{Methods}

\section{Surveys}

There are nine black abalone monitoring sites distributed around the island and each consists of two to seven permanent transects (fig. 1). These transects range in length from 7 to $40 \mathrm{~m}$ (table 1) depending on the availability of suitable habitat. They were established in areas that supported high densities of black abalone at the time and provide good coverage around the island. The transects are excellent for tracking trends, but because they were not randomly placed, they cannot be used to estimate a more general population size or density. The transect locations are marked by multiple stainless-steel eyebolts, typically 5-10 m apart, that are epoxied into holes drilled in the substrate. During surveys, a meter tape is attached to the eyebolts and a 2-m-wide area centered on the transect is surveyed along the entire length of the transect. To provide better repeatability of effort and allow for finer scale data assessments, the belt transects are further divided into $1-\mathrm{m}^{2}$ quadrats on either side of the transect tape so that a $30-\mathrm{m}$ transect has 60 quadrats and samples $60 \mathrm{~m}^{2}$ of area. The only exceptions are at site 2 where transects 3 and 4 are treated as $1-\mathrm{m}$ wide because the transect tapes there each run along a single crevice for their entire length. The total sampled area for all nine sites is $2,054 \mathrm{~m}^{2}$. However, the actual area sampled is much greater because of the heterogeneity of the rocky shore including numerous crevices, ridges, and boulders.

For safety, sampling was conducted during day-time negative low tides. Sampling cycles began January 1st and were completed during the winter if possible, because from April through October, most low tides of workable magnitude at SNI occurred during dark hours (at night or early morning). The order in which sites were sampled was determined largely by tidal height and surf conditions. 
Table 1. Numbers of transects and their lengths and areas at each site, San Nicolas Island, California. - Continued

[Most transects are 2 meters $(\mathrm{m})$ wide. Those marked with * are $1 \mathrm{~m}$ wide (see "Methods" section)].

\begin{tabular}{|c|c|c|}
\hline Transect & Length & Area \\
\hline \multicolumn{3}{|c|}{ Site 1} \\
\hline 1 & 30 & 60 \\
\hline 2 & 30 & 60 \\
\hline 3 & 30 & 60 \\
\hline 4 & 30 & 60 \\
\hline 5 & 30 & 60 \\
\hline 6 & 30 & 60 \\
\hline \multicolumn{3}{|c|}{ Site 2} \\
\hline 1 & 30 & 60 \\
\hline 2 & 30 & 60 \\
\hline $3 *$ & 17 & 17 \\
\hline $4 *$ & 27 & 27 \\
\hline 5 & 30 & 60 \\
\hline 6 & 25 & 50 \\
\hline \multicolumn{3}{|c|}{ Site 3} \\
\hline 1 & 31 & 62 \\
\hline 2 & 35 & 70 \\
\hline 3 & 36 & 72 \\
\hline 4 & 7 & 14 \\
\hline 5 & 8 & 16 \\
\hline 6 & 15 & 30 \\
\hline 7 & 18 & 36 \\
\hline \multicolumn{3}{|c|}{ Site 4} \\
\hline 1 & 12 & 24 \\
\hline 2 & 14 & 28 \\
\hline \multicolumn{3}{|c|}{ Site 5} \\
\hline 1 & 15 & 30 \\
\hline 2 & 12 & 24 \\
\hline 3 & 8 & 16 \\
\hline
\end{tabular}

\begin{tabular}{|c|c|c|}
\hline Transect & Length & Area \\
\hline \multicolumn{3}{|c|}{ Site 6} \\
\hline 1 & 26 & 52 \\
\hline 2 & 30 & 60 \\
\hline 3 & 30 & 60 \\
\hline 4 & 40 & 80 \\
\hline \multicolumn{3}{|c|}{ Site 7} \\
\hline 1 & 30 & 60 \\
\hline 2 & 30 & 60 \\
\hline 3 & 25 & 50 \\
\hline 4 & 25 & 50 \\
\hline 5 & 25 & 50 \\
\hline \multicolumn{3}{|c|}{ Site 8} \\
\hline 1 & 30 & 60 \\
\hline 2 & 30 & 60 \\
\hline 3 & 30 & 60 \\
\hline 4 & 25 & 50 \\
\hline 5 & 24 & 48 \\
\hline \multicolumn{3}{|c|}{ Site 9} \\
\hline 1 & 18 & 36 \\
\hline 2 & 7 & 14 \\
\hline 3 & 10 & 20 \\
\hline 4 & 20 & 40 \\
\hline 5 & 27 & 54 \\
\hline 6 & 17 & 34 \\
\hline
\end{tabular}

Each quadrat was carefully searched for black abalone with the aid of handheld lights to assist searching cracks and crevices. If possible, those found were measured for maximum shell length with dividers to the nearest millimeter (fig. 3). Frequently, it was not possible to obtain a measurement because abalone often occur in crevices where they could not be reached or where measuring tools could not be used. The target sample size for shell measurements was 200 per site. Beginning in sampling cycle 29 (2019), most inaccessible abalone and those encountered after 200 measurements at a site were assigned by visual estimation to one of two size bins:

less than $3.5 \mathrm{~cm}$ (recruit) or greater than or equal to $3.5 \mathrm{~cm}$ (non-recruit), thus giving more information on recruitment dynamics. In prior years, no effort was made to estimate size classes for unmeasured individuals. At the 2 sites where there were more than 200 abalone, sites 7 and 8 , the transects were sampled in the same order and from the same starting point each year to reduce temporal and observer sampling error in the size data. Since 2013, the actual number of abalone measured usually exceeded the target number at both these sites. At the remaining sites, transect sampling order was determined by field conditions. 

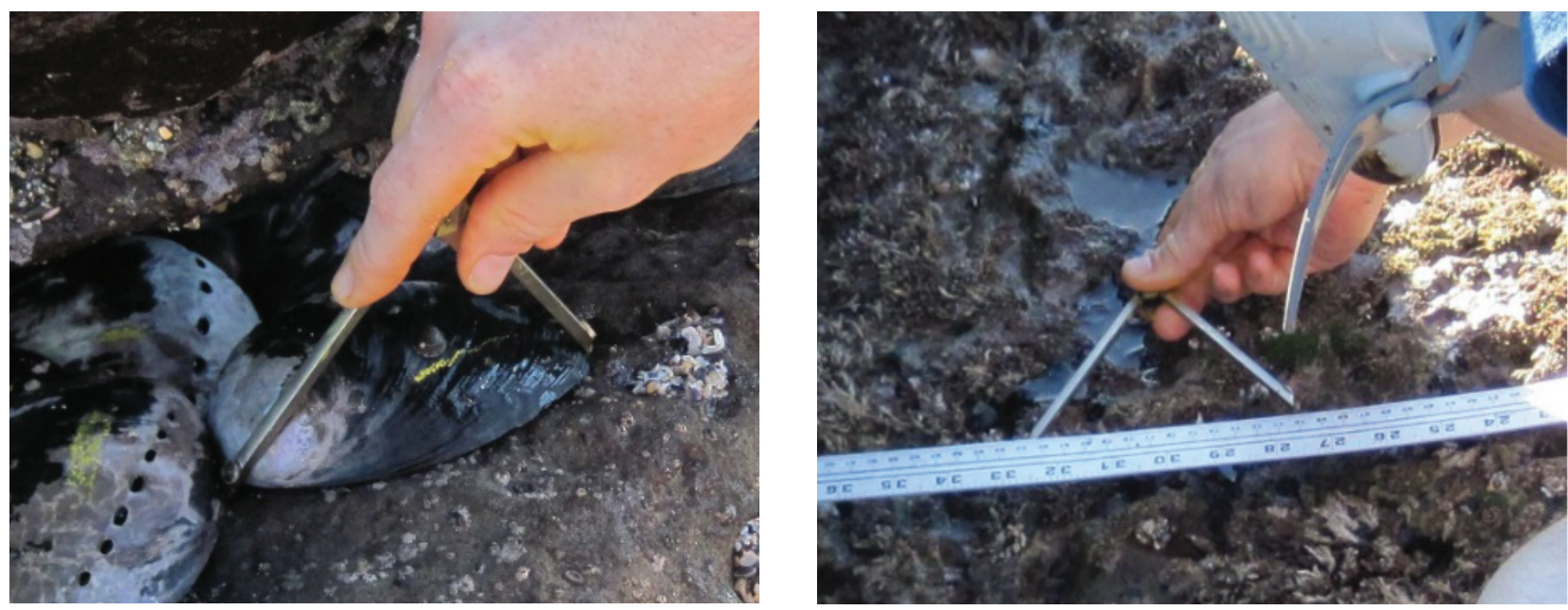

Figure 3. Shell length is measured to the nearest millimeter by using dividers and a ruler, San Nicolas Island (SNI), California. Photographs taken by M.C. Kenner, U.S. Geological Survey, January 22, 2019.

For every black abalone, including non-measured individuals, the distance to the closest conspecific found (nearest neighbor) was measured (or estimated) to the nearest centimeter; nearest neighbors were recorded even if they occurred outside of the quadrats. In addition, the microhabitat of each abalone was recorded as one of three classes: (1) open horizontal, (2) open vertical, or (3) crevice. The first two categories are characterized by open, non-cryptic habitats that are either less than or greater than a 45-degree $\left(^{\circ}\right)$ angle from a horizontal plane. Crevice habitat consists of cracks, crevices, or pockets of any orientation. Additionally, the cover of exposed sand was estimated to the nearest 10 percent for each quadrat. The presence and relative abundance of sea urchins in each quadrat as well as the radius length of all sea star species found on the transects also were recorded.

Unavoidably, counts were made with error because some abalone remained hidden in cryptic rock or biological refugia despite efforts to thoroughly search for them. In addition, surging water during unfavorable tides or surf events sometimes complicated field efforts.

\section{Statistical Analysis}

Generalized additive models (GAMs) were used to analyze abalone counts by site for the recovery period from 2001 to 2020. The counts were modeled as an overdispersed Poisson distribution as a nonlinear function of year. The quasi poisson distribution was utilized with the gam function from the "mgcv" package in R statistical software (https://www.r-project.org/) to estimate overdispersion (data dispersion beyond that expected from a Poisson model) and to fit GAMs to the abalone count data; the "s" function was used to represent trends as a smooth spline function based on year (Hastie and Pregibon, 1992; R Core Team, 2017; Wood, 2017).
Using apparent inflexions in the growth curve for the total SNI count, the periods 2001-07, 2007-14, 2014-20, and the whole period from 2001 to 2020 were examined. Period percentage changes were calculated as follows:

$$
\left(N_{2}-N_{1}\right) / N_{1} \times 100 \%
$$

where

$$
\begin{gathered}
N_{1} \quad \begin{array}{c}
\text { is the GAM-based estimate of mean abalone } \\
\text { sums from the first year of a period, and }
\end{array} \\
N_{2} \quad \begin{array}{c}
\text { is the GAM-based estimate of mean abalone } \\
\text { sums from the last year of a period. }
\end{array}
\end{gathered}
$$

Percent per annum changes also were calculated for each period from annualized rates of growth:

$$
\left(\left(N_{2} / N_{1}\right)^{1 / y}-1\right) \times 100 \%
$$

where

$$
\begin{gathered}
N_{1} \quad \text { is the GAM-based estimate of mean abalone } \\
\text { sums from the first year of a period, } \\
N_{2} \quad \text { is the GAM-based estimate of mean abalone } \\
\text { sums from the last year of a period, and } \\
\text { y is the number of years in the period of } \\
\text { interest. }
\end{gathered}
$$

\section{Sites}

This section includes a brief description of the nine sites around the island. Refer to figure 1 for locations. Photographs of most of the transects, taken between 2016 and 2020, can be found in Kenner, 2020. 
Site 1 is in Bomber Cove on the north side of Vizcaino Point on SNI. There are six parallel transects arranged perpendicular to the shore spaced approximately $50 \mathrm{~m}$ apart from each other. Transect 1 follows along the base of a rock outcropping measuring several meters high. Transects $2-6$ are on low bedrock with scattered boulders, approximately $0.25-0.75 \mathrm{~m}$ high. Surfgrass (Phyllospadix spp.), anemones (Anthopleura spp.), and purple urchins (Strongylocentrotus purpuratus) are common in the lower areas. The site is fairly exposed to the prevailing northwest swell.

Site 2 is in the Thousand Springs area on the northernmost point of the island. The six transects are scattered into three general areas with approximately $900 \mathrm{~m}$ between the westernmost and easternmost transects. Transects 1 and 2 parallel each other along pools on the main point near the range marker poles. Transects $3-5$ are several hundred meters to the east in a combination of crevice (transects 3 and 4) and red algal clad boulder (transect 5) habitat. Transect 6 , several hundred meters further to the east, runs along a broad flat bench with parallel pools and rockweed (Silvetia compressa) cover.

Site 3 spans approximately $1,600 \mathrm{~m}$ from transect 1 , west to transect 7 in three areas along the northeast shore. Transects 1-3 parallel the shore along a narrow rocky bench at the base of a steep bank below the northwest end of the runway. Transects 1 and 3 are typically covered by the coralline alga Corallina vancouverensis and the red alga Mazzaella affinis. However, transect 2 has been mostly bare since 2015, likely due to a sand burial event that eliminated abalone on transects 1 and 2. Transects 4-6 are clustered together on a fairly bare rock bench approximately $975 \mathrm{~m}$ to the west. Transect 7, another $640 \mathrm{~m}$ westward, is on a narrow C. vancouverensis covered rock ridge situated between a channel-like pool and the ocean.

Site 4, south of the east end sand spit, is the smallest of the sites. Although a challenge to access, it consists of only two parallel transects, a few meters apart, on a raised mussel (Mytilus californianus) covered intertidal bench.

Site 5, on the southeast shore of the island, has three transects parallel to shore spaced about $10 \mathrm{~m}$ apart on a slightly elevated bench covered with $M$. californianus.

Site 6, near the old navigation light on the southeast shore of the island, consists of four transects spread out over about $300 \mathrm{~m}$. All of the transects are on fairly flat $M$. californianus beds with some large patches of Phyllospadix spp.

Site 7, near the south side range marker poles, has five transects arranged upon one large rocky bench. Transect 1 is along the raised eastern edge of the reef. Transects 2 and 3 follow channels on top of the reef and intersect each other at about a $90^{\circ}$ angle. Transects 4 and 5 are about approximately $150 \mathrm{~m}$ west of transect 1 and traverse channels and crevices perpendicular to the shore in a jumbled, high relief area of the reef susceptible to sand incursion.

Site 8 , on the southwest shore, is made up of five transects spread out over about $230 \mathrm{~m}$. Transect 1 is on a low, flat ridge between two pools where a few boulders provide some cryptic habitat. Transects 2 and 3 are parallel to each other and follow low ridges with abundant crevice space. To the east, transects 4 and 5 also parallel each other and traverse channels dominated by boulders and are susceptible to sand influence.

Site 9 is to the south of "Rock Crusher" on the west end of the island where it is fully exposed to the predominant westerly swells. Six transects are spread over approximately $170 \mathrm{~m}$ across an extensive low rock reef. The transects follow low ledges in an area with numerous boulders. Corallina vancouverensis and Phyllospadix spp. provide most of the cover.

\section{Results}

The 2020 (cycle 30) sampling of the sites took place between January 7 and February 8, 2020, and was spread out over three trips to the island. Generally, good conditions prevailed during the trips, with only a few days characterized by large surf.

\section{Counts}

A total of 2,341 abalone were counted on all nine sites in $2020\left(2,054 \mathrm{~m}^{2}\right.$ sampled). This is the highest count since 1992-93 (cycle 8) when 20,334 abalone were counted during the time WS was just beginning to affect the SNI population. It also is the first time since 1996 that the average island-wide density exceeded one abalone per $\mathrm{m}^{2}$ sampled. The 2020 total count was 15.8 percent higher than the 2019 total and continues a generally positive growth trend apparent since regular annual counts were resumed in 2001. Figure 4 shows the raw total count from each survey plotted from 2001 to 2020, the calculated GAM curve, and the 95-percent confidence band (adjusted $\mathrm{R}^{2}=0.986$ ).

The population trend during this period showed three general phases. During the initial 7 years, from 2001 to 2007, total black abalone counts showed a relatively modest increase of 128 percent ( 15 percent per annum). This modest increase was followed by a higher growth period from 2007 to 2014, with an increase of 285 percent (21 percent per annum). During the last 7 years, from 2014 to 2020, growth returned to a slower rate, increasing only 38 percent ( 6 percent per annum), but the 15.8 percent growth in 2020 was slightly above the per annum growth of 14 percent during the 2001-20 period. 


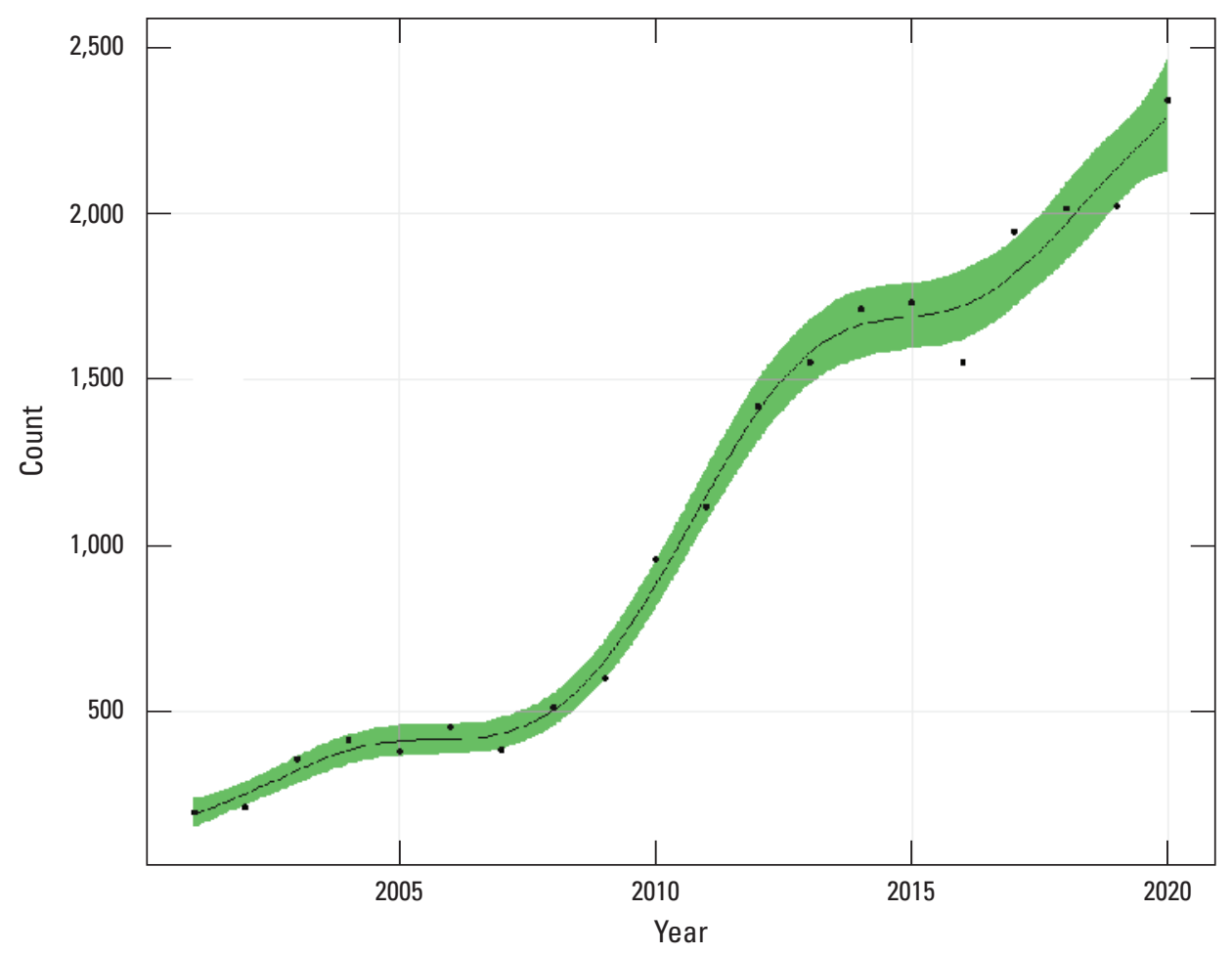

Figure 4. Total black abalone counts, generalized additive model nonlinear regression, and 95-percent confidence band, San Nicolas Island, California, 2001-20.

Population growth was inconsistent across sites (table 2). The confidence intervals for the growth rates of some of the sites were quite large during some of the periods (and as a result, for the entire 19-year period). Three of the sites (sites 1,3, and 5) displayed negative change during the recent period from 2014 to 2020. Additionally, site 1 declined during the first period (2001-07) and site 5 declined during the second period (2007-14) when many sites had their highest population growth rate. Site 2 and 9 had consistent per annum rates of growth across the three periods of 17 and 11 percent, respectively. Site 5 had the lowest rate of growth during the entire period, with a per annum rate of 5 percent, whereas site 4 and 6 had the highest (28 percent). Site 8 , which accounts for nearly half the surveyed population (largely due to the higher number of black abalone surviving there in 2001), had a very modest rate of increase (11 percent). Figure 5 shows the count trajectories, as well as the calculated GAM curve, and the 95-percent confidence band, for each of the sites and the total SNI count on a log scale to simplify comparison.

Figure 6 shows the counts at each of the sites during the course of the project from 1981 to 2020. An inset graph of the last 20 years with an expanded y-axis gives a better view of the recovery trends at the sites during this time.

Figure 7 shows how the counts at the different sites contributed to the total count from 2001 to 2020. During this time, site 8 contributed the most to the overall count; site 7 became a major contributor as well (beginning in 2010). Beginning in 2018, site 6 black abalone abundances increased substantially.

Table 3 displays counts for each site during the entire course of the sampling program. Missing data from unsampled transects in the early 1980s (see the "Project History" section) were estimated for purposes of obtaining average pre-WS counts and densities. Cycle 2 values were used as estimates for missing cycle 1 counts for transect 4 of site 7 . Missing cycle 2 data for site 2, site 8 and transect 6 of site 1 were estimated by averaging the counts for those locations from cycle 1 and cycle 3 . No attempt was made to estimate missing cycle 8 data because the population was in decline at that time. The average total count during the pre-WS period (1981-91) was 24,387 individuals. Although the count fell to 0.8 percent of that total in 2001, mostly positive growth for 19 years brought the 2020 count to 9.6 percent of the pre-WS average total. Mean densities at the sites ranged from 4.0 to 27.8 per $\mathrm{m}^{2}$ (11.9 per $\mathrm{m}^{2}$ average) during the pre-WS period. As of the 2020 field season, mean site densities ranged from

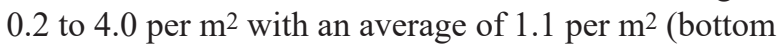
green row in table 3). Unlike 2019, when six of the nine sites showed declines in total count from the previous year, all sites increased in 2020, ranging from 8.5 percent to 165.5 percent (blue row in table 3 ). 
Table 2. Period (top) and per annum (bottom) percentage changes in mean black abalone counts during given periods calculated from generalized additive model (GAM) analysis, San Nicolas Island, California, 2001-20.

[Values in parentheses () indicate 95-percent confidence range].

\begin{tabular}{|c|c|c|c|}
\hline 2001-07 & 2007-14 & 2014-20 & $2001-20$ \\
\hline \multicolumn{4}{|c|}{ Site 1} \\
\hline$-15(-71,152)$ & $721(349,1,400)$ & $38(-11,114)$ & $861(252,2,520)$ \\
\hline$-3(-19,17)$ & $35(24,47)$ & $5(-2,14)$ & $13(7,19)$ \\
\hline \multicolumn{4}{|c|}{ Site 2} \\
\hline $158(20,455)$ & $202(91,377)$ & $158(79,271)$ & $1,900(881,4,000)$ \\
\hline $17(3,33)$ & $17(10,25)$ & $17(10,24)$ & $17(13,22)$ \\
\hline \multicolumn{4}{|c|}{ Site 3} \\
\hline $1,290(125,8,440)$ & $395(202,710)$ & $-67(-82,-41)$ & $2,170(259,14,300)$ \\
\hline $55(15,110)$ & $26(17,35)$ & $-17(-25,-8)$ & $18(7,30)$ \\
\hline \multicolumn{4}{|c|}{ Site 4} \\
\hline $659(17,4,840)$ & $588(229,1,340)$ & $118(33,257)$ & $11,300(1,800,68,000)$ \\
\hline $40(3,92)$ & $32(19,46)$ & $14(5,24)$ & $28(17,41)$ \\
\hline \multicolumn{4}{|c|}{ Site 5} \\
\hline $249(66,632)$ & $-9(-38,34)$ & $-26(-59,34)$ & $136(0,459)$ \\
\hline $23(9,39)$ & $-1(-7,4)$ & $-5(-14,5)$ & $5(0,9)$ \\
\hline \multicolumn{4}{|c|}{ Site 6} \\
\hline $298(46,984)$ & $467(243,835)$ & $409(276,589)$ & $11,400(4,470,28,600)$ \\
\hline $26(7,49)$ & $28(19,38)$ & $31(25,38)$ & $28(22,35)$ \\
\hline \multicolumn{4}{|c|}{ Site 7} \\
\hline $128(7,386)$ & $1,130(786,1,620)$ & $32(10,57)$ & $3,600(1,730,7,370)$ \\
\hline $15(1,30)$ & $43(37,50)$ & $5(2,8)$ & $21(17,26)$ \\
\hline \multicolumn{4}{|c|}{ Site 8} \\
\hline $106(54,174)$ & $170(132,214)$ & $36(19,56)$ & $657(472,902)$ \\
\hline $13(7,18)$ & $15(13,18)$ & $5(3,8)$ & $11(10,13)$ \\
\hline \multicolumn{4}{|c|}{ Site 9} \\
\hline $91(12,226)$ & $113(53,196)$ & $91(40,162)$ & $676(359,1,210)$ \\
\hline $11(2,22)$ & $11(6,17)$ & $11(6,17)$ & $11(8,15)$ \\
\hline \multicolumn{4}{|c|}{ SNI total } \\
\hline $128(77,194)$ & $284(239,335)$ & $38(25,52)$ & $1,110(847,1,440)$ \\
\hline $15(10,20)$ & $21(19,23)$ & $6(4,7)$ & $14(13,16)$ \\
\hline
\end{tabular}



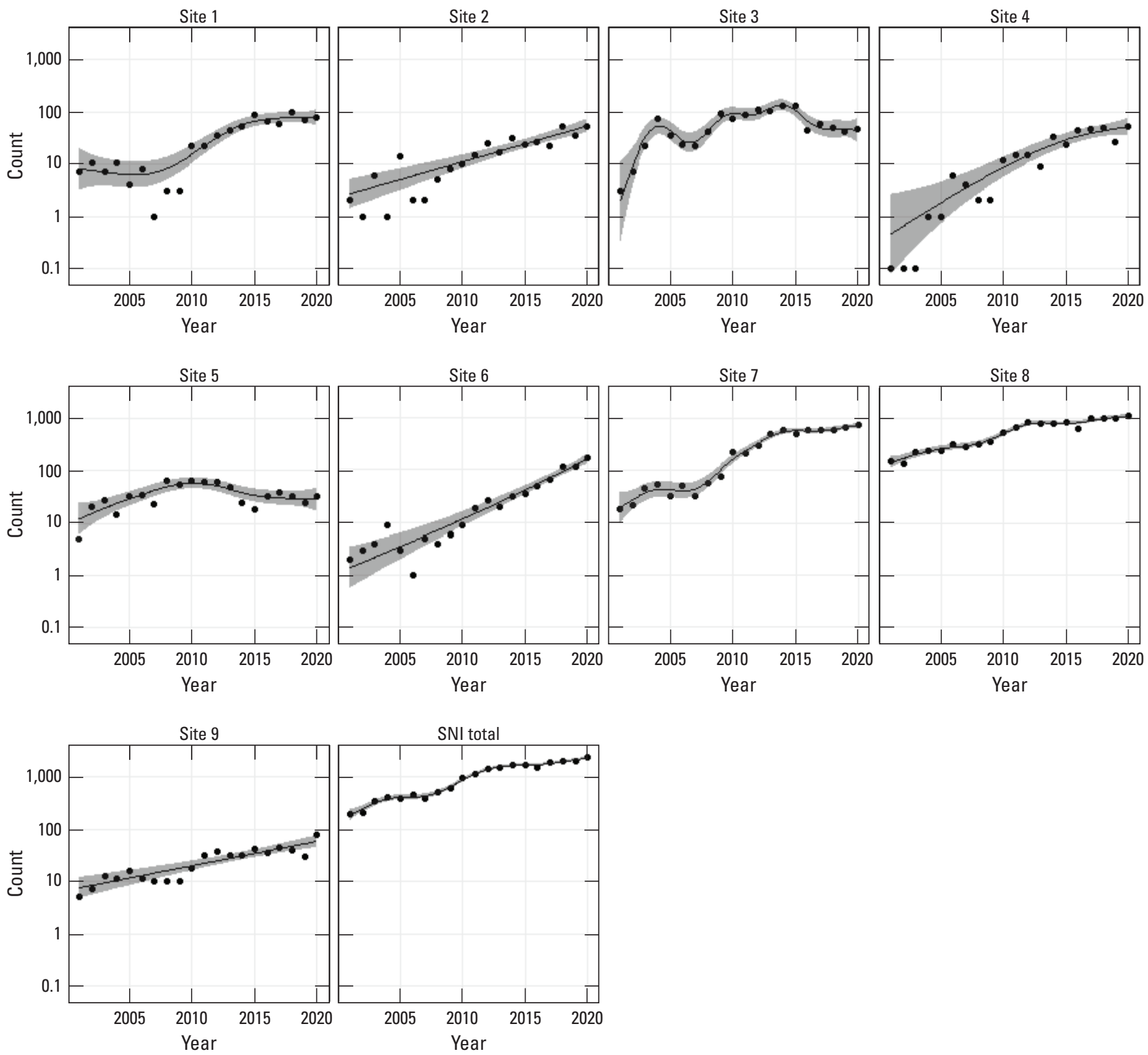

Figure 5. Black abalone count at each site and island total at San Nicolas Island, California, plotted on a log scale, 2001-20. Curves and 95 -percent confidence bands were generated by generalized additive model. (Zero values displayed as 0.1 to allow plotting on the log-scaled axis). 


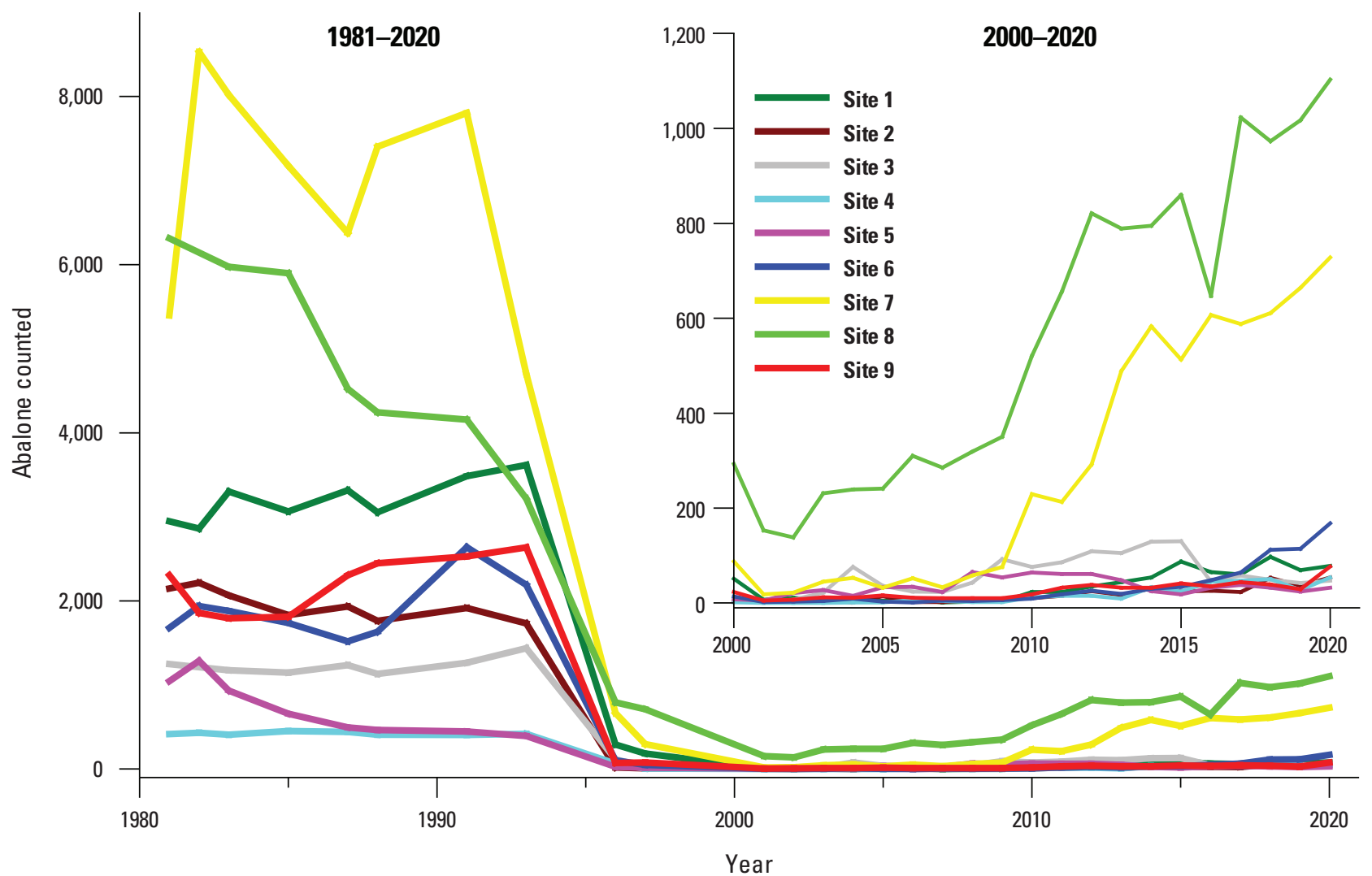

Figure 6. Total black abalone count at each of the nine San Nicolas Island, California, sites during the course of the study (1981-2020) and the 2001-20 recovery phase following the withering syndrome outbreak (inset).

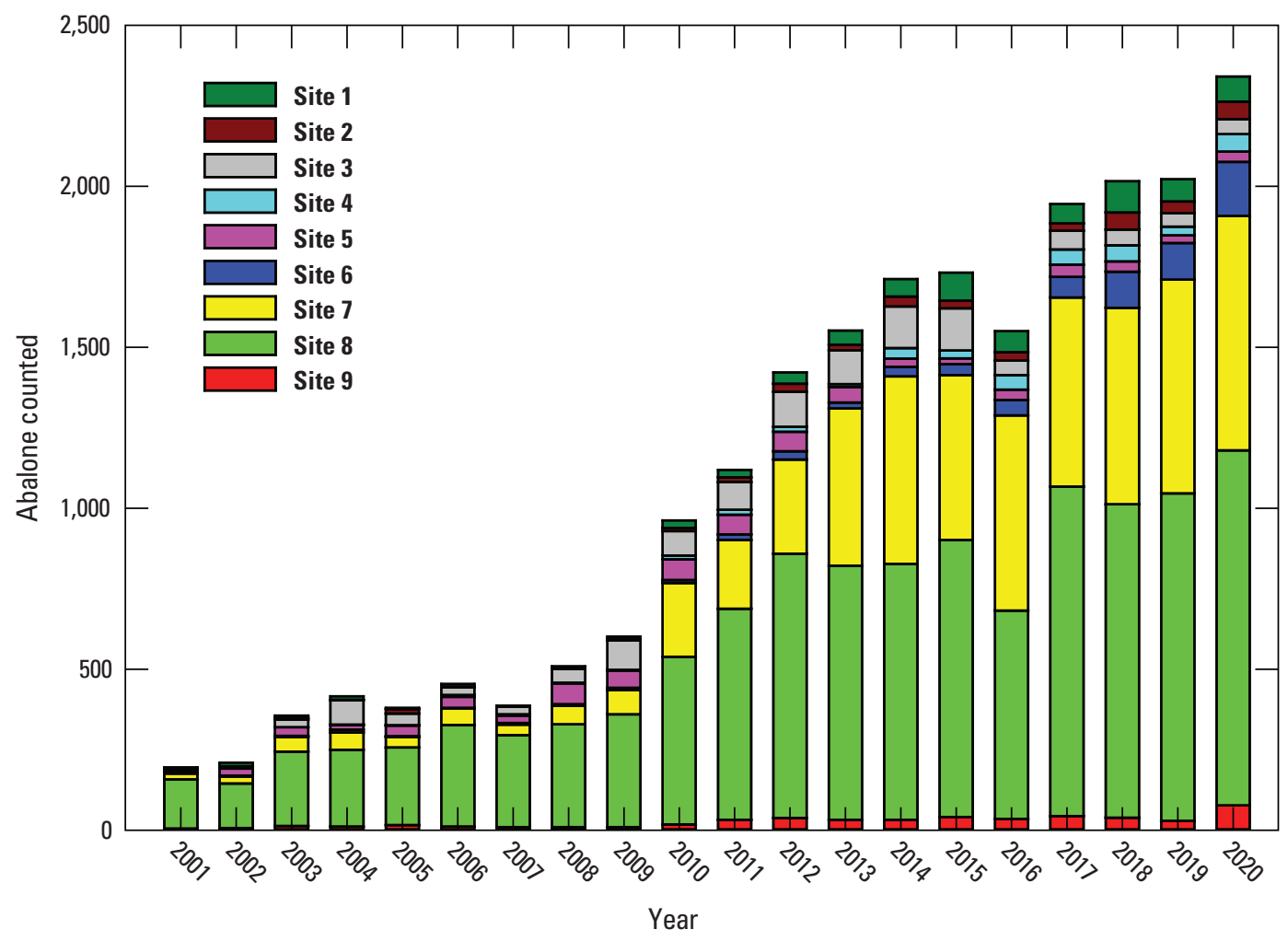

Figure 7. Contribution (by site) to total black abalone counts for 2001-20, San Nicolas Island, California. 
Table 3. Counts (by site) for each sampling cycle, San Nicolas Island, California, 1981-2020.

[Far right column has cycle total. Average count and average density for pre-WS years shown after cycle 7. Percent change from 2019 to 2020 and density in 2020 at each site and overall also shown. Asterisk (*) indicates some sites or transects were not sampled and total includes interpolated counts (see "Project History" section for details). Abbreviation: $\mathrm{m}^{2}$, square meter].

\begin{tabular}{|c|c|c|c|c|c|c|c|c|c|c|c|}
\hline Cycle & Year completed & Site 1 & Site 2 & Site 3 & Site 4 & Site 5 & Site 6 & Site 7 & Site 8 & Site 9 & $\begin{array}{l}\text { Cycle } \\
\text { total }\end{array}$ \\
\hline 1 & 1981 & 2,946 & 2,146 & 1,247 & 415 & 1,044 & 1,677 & $* 7,138$ & 6,313 & 2,304 & $* 25,230$ \\
\hline 2 & 1982 & $* 3,227$ & 2,215 & $* 1,210$ & 431 & 1,286 & 1,938 & 8,531 & $* 6,144$ & 1,856 & $* 26,838$ \\
\hline 3 & 1983 & 3,300 & 2,065 & 1,174 & 408 & 933 & 1,880 & 8,019 & 5,975 & 1,792 & 25,546 \\
\hline 4 & 1985 & 3,062 & 1,830 & 1,147 & 450 & 657 & 1,737 & 7,177 & 5,899 & 1,811 & 23,770 \\
\hline 5 & 1987 & 3,314 & 1,933 & 1,235 & 442 & 495 & 1,517 & 6,377 & 4,523 & 2,303 & 22,139 \\
\hline 6 & 1988 & 3,053 & 1,763 & 1,131 & 407 & 465 & 1,631 & 7,403 & 4,245 & 2,446 & 22,544 \\
\hline 7 & 1991 & 3,482 & 1,916 & 1,263 & 405 & 446 & 2,638 & 7,806 & 4,158 & 2,528 & 24,642 \\
\hline \multicolumn{2}{|c|}{ Average count for cycles 1-7 } & $3,197.7$ & $1,981.1$ & $1,201.0$ & 422.6 & 760.9 & $1,859.7$ & $7,493.0$ & $5,322.4$ & $2,148.6$ & $24,387.0$ \\
\hline \multicolumn{2}{|c|}{ Average density / $\mathrm{m}^{2}$ for cycles $1-7$} & 8.9 & 7.2 & 4.0 & 8.1 & 10.9 & 7.4 & 27.8 & 19.2 & 10.9 & 11.9 \\
\hline 8 & 1993 & 3,625 & 1,731 & 1,435 & 417 & 392 & 2,190 & 4,702 & 3,216 & 2,635 & 20,334 \\
\hline 9 & 1996 & 290 & 18 & 115 & 63 & 26 & 102 & 666 & 792 & 72 & 2,144 \\
\hline 10 & 1997 & 183 & 8 & 21 & 6 & 17 & 48 & 297 & 712 & 78 & 1,370 \\
\hline 11 & 2001 & 7 & 2 & 3 & 0 & 5 & 2 & 18 & 153 & 5 & 195 \\
\hline 12 & 2002 & 11 & 1 & 7 & 0 & 21 & 3 & 22 & 138 & 7 & 210 \\
\hline 13 & 2003 & 7 & 6 & 22 & 0 & 27 & 4 & 45 & 231 & 12 & 354 \\
\hline 14 & 2004 & 11 & 1 & 76 & 1 & 15 & 9 & 53 & 239 & 11 & 416 \\
\hline 15 & 2005 & 4 & 14 & 36 & 1 & 33 & 3 & 32 & 241 & 16 & 380 \\
\hline 16 & 2006 & 8 & 2 & 24 & 6 & 34 & 1 & 52 & 310 & 11 & 448 \\
\hline 17 & 2007 & 1 & 2 & 23 & 4 & 23 & 5 & 33 & 285 & 10 & 386 \\
\hline 18 & 2008 & 3 & 5 & 43 & 2 & 65 & 4 & 58 & 319 & 10 & 509 \\
\hline 19 & 2009 & 3 & 8 & 92 & 2 & 54 & 6 & 76 & 350 & 10 & 601 \\
\hline 20 & 2010 & 23 & 10 & 76 & 12 & 64 & 9 & 229 & 521 & 18 & 962 \\
\hline 21 & 2011 & 23 & 15 & 86 & 15 & 61 & 18 & 213 & 656 & 32 & 1,119 \\
\hline 22 & 2012 & 35 & 25 & 109 & 15 & 61 & 26 & 292 & 821 & 38 & 1,422 \\
\hline 23 & 2013 & 44 & 17 & 105 & 9 & 48 & 19 & 489 & 789 & 32 & 1,552 \\
\hline 24 & 2014 & 54 & 31 & 129 & 33 & 25 & 30 & 583 & 795 & 32 & 1,712 \\
\hline 25 & 2015 & 87 & 24 & 130 & 24 & 18 & 34 & 513 & 860 & 41 & 1,731 \\
\hline 26 & 2016 & 65 & 26 & 45 & 45 & 32 & 48 & 607 & 647 & 35 & 1,550 \\
\hline 27 & 2017 & 60 & 23 & 58 & 47 & 38 & 64 & 588 & 1,023 & 44 & 1,945 \\
\hline 28 & 2018 & 97 & 53 & 49 & 50 & 32 & 112 & 611 & 973 & 39 & 2,016 \\
\hline 29 & 2019 & 69 & 36 & 42 & 27 & 24 & 114 & 664 & 1,017 & 29 & 2,022 \\
\hline 30 & 2020 & 78 & 54 & 47 & 54 & 32 & 168 & 728 & 1,103 & 77 & 2,341 \\
\hline \multicolumn{12}{|c|}{ Percent change from 2019 to 2020} \\
\hline - & - & 13.0 & 50.0 & 11.9 & 100.0 & 33.3 & 47.4 & 9.6 & 8.5 & 165.5 & 15.8 \\
\hline \multicolumn{12}{|c|}{ Density / $\mathrm{m}^{2}$ in 2020} \\
\hline- & - & 0.2 & 0.2 & 0.2 & 1.0 & 0.5 & 0.7 & 2.7 & 4.0 & 0.4 & 1.1 \\
\hline
\end{tabular}


Figures $8-16$ show how the counted abalone were distributed along each transect during the 2018-20 sampling period. On each graph, the $\mathrm{x}$-axis (quadrat number) is scaled for the longest transect at each site and the y-axis (number of abalone) for the highest count in a quadrat at the site. Zero abalone were counted on 6 of the 44 transects in 2020. For comparison, five transects in 2019, and seven in 2018 had zero abalone counted. Abalone on the transects exhibit a clumped distribution. Although there was some minor shuffling of quadrat densities, the distribution along the transects was fairly consistent among these 3 years. In 2020 , the highest quadrat count was 69 abalone compared to 74 in 2019 and 62 in 2018. Of the 2,054 total $1-\mathrm{m}^{2}$ quadrats, there was a decline in the number having zero abalone from 1,735 quadrats in 2019 to 1,649 in 2020 . There was no change in the count in 1,608 quadrats. Of the 405 quadrats that had abalone in 2020, 58 had the same number as in 2019. Of the 347 quadrats that did change, 284 increased compared to
63 that decreased. More than 80 percent of those that changed did so by 5 abalone or less, but differences ranged from an increase of 51 abalone to a decrease of 70 .

The crevice microhabitat category was the most commonly observed. Between 1983, when microhabitat was first recorded, and 1993, an average 65.9 percent of sampled abalone were in this category. In surveys conducted after the WS induced population decline (2001-20), the average jumped to 95.0 percent. In 2020, more than 92 percent of abalone recorded were in the crevice microhabitat. Table 4 shows the utilization of different microhabitat categories among sites in 2020. Site 6, which had the least amount of relief and complexity, was the only location where crevice was not the dominant category. Instead, at site $6,31.0$ percent of abalone occurred on open horizontal and 15.5 percent were on open vertical habitats in 2020 . The greater utilization of exposed microhabitats pre-WS was likely a result of crowding of more preferred habitats. 

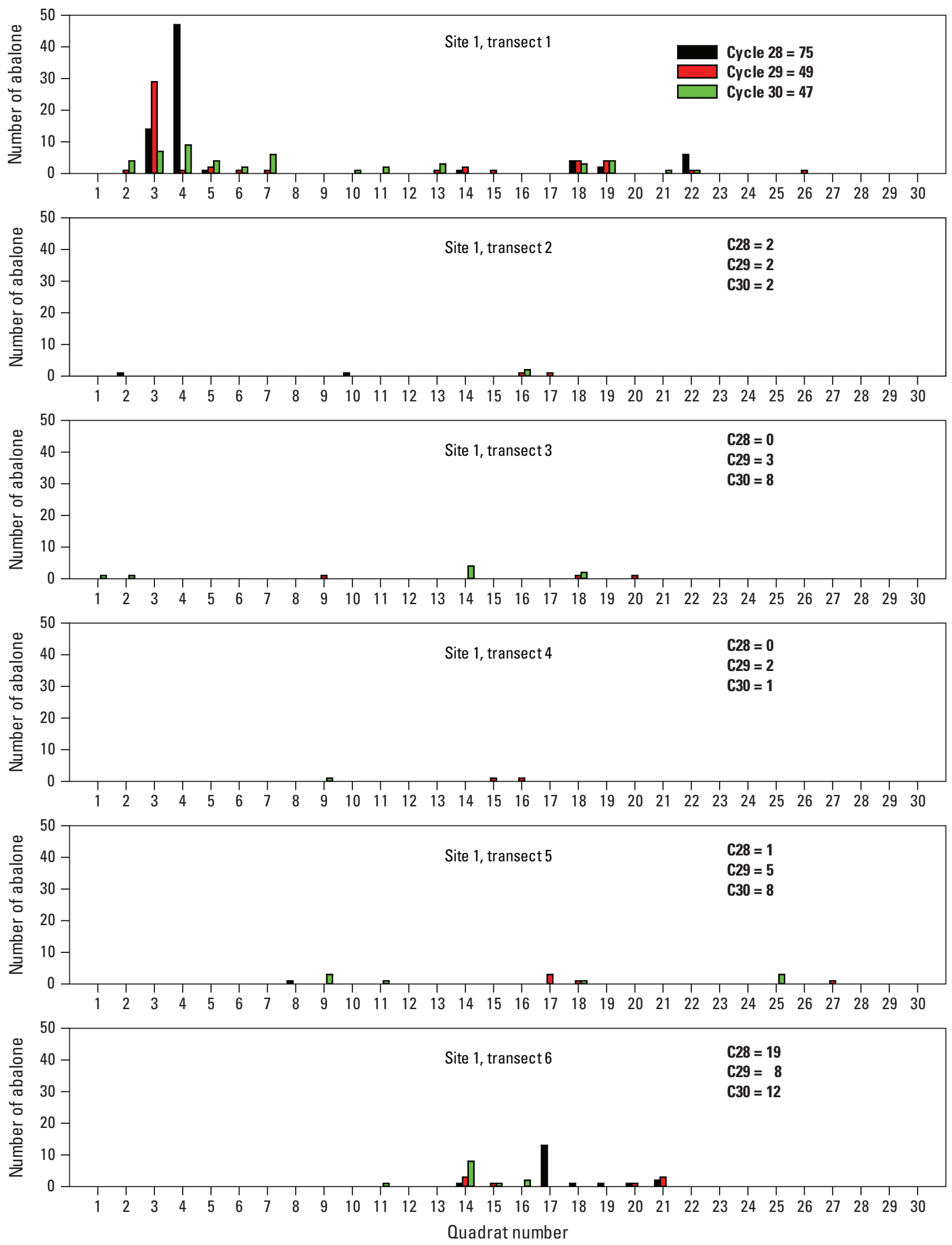

Figure 8. Cycle 28 (black bars), cycle 29 (red bars), and cycle 30 (green bars) distribution of black abalone along transects at site 1, San Nicolas Island, California, 2018-20. Total transect count for each cycle indicated on graph. 

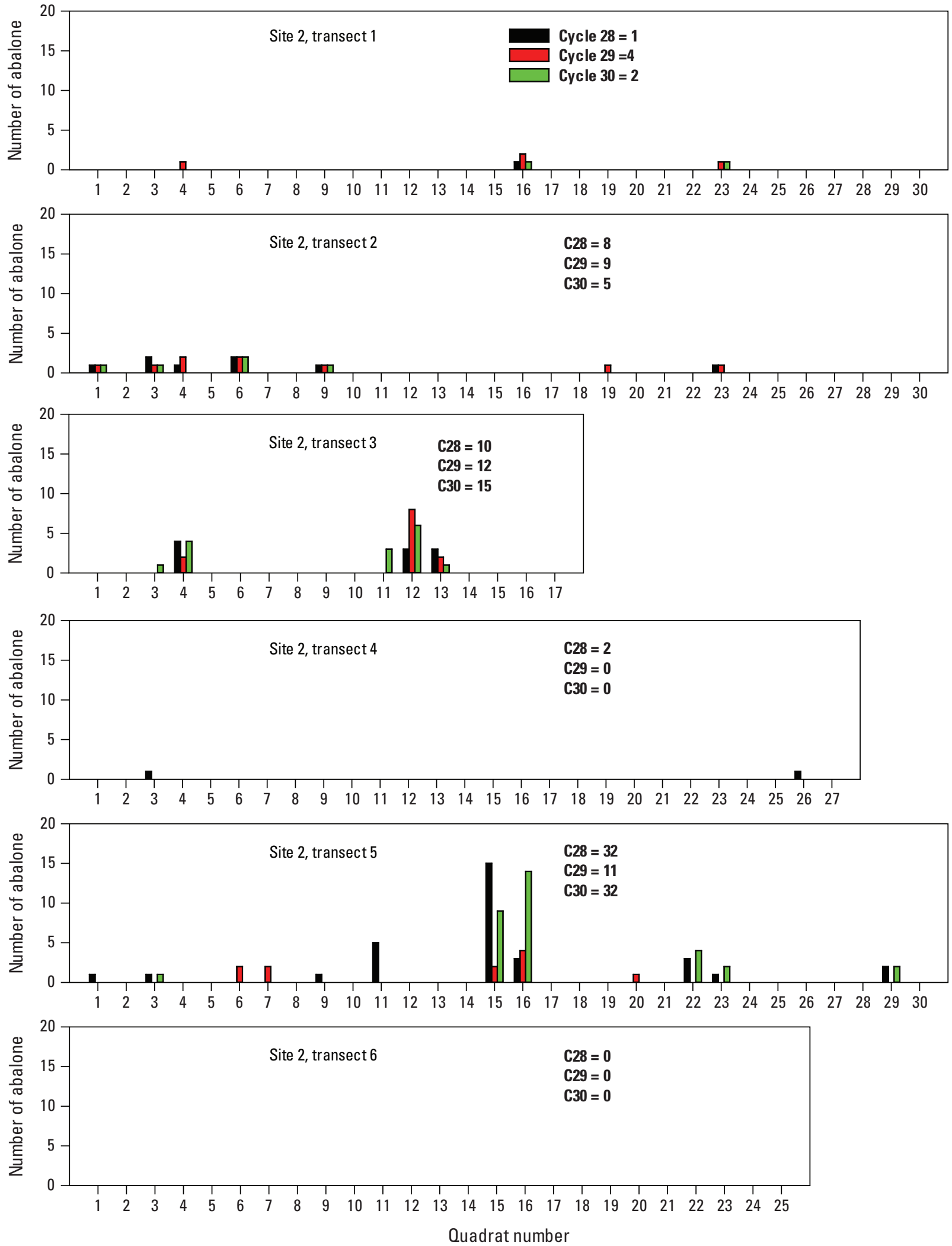

Figure 9. Cycle 28 (black bars), cycle 29 (red bars), and cycle 30 (green bars) distribution of black abalone along transects at site 2, San Nicolas Island, California, 2018-20. Total transect count for each cycle indicated on graph. 

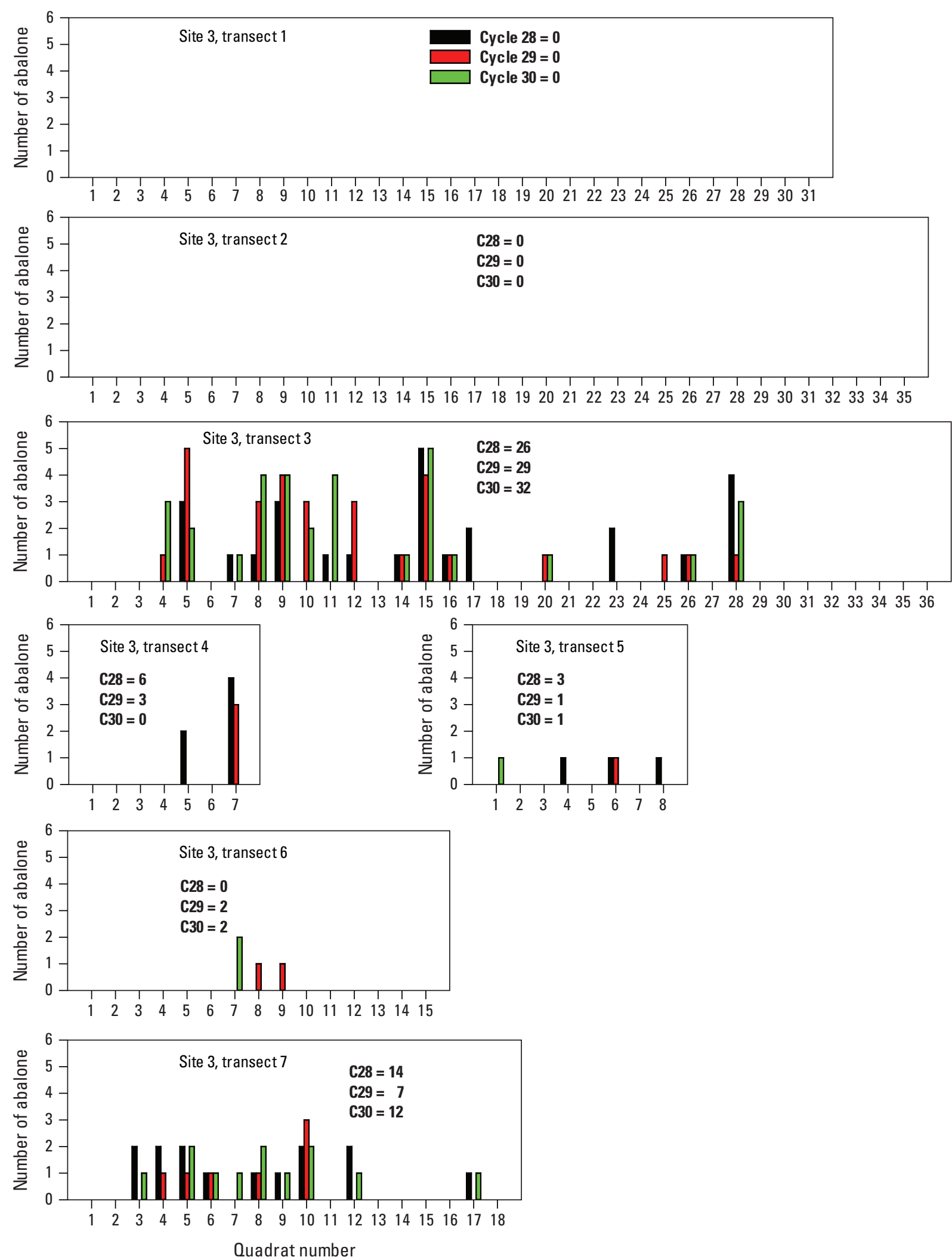

Figure 10. Cycle 28 (black bars), cycle 29 (red bars), and cycle 30 (green bars) distribution of black abalone along transects at site 3, San Nicolas Island, California, 2018-20. Total transect count for each cycle indicated on graph. 

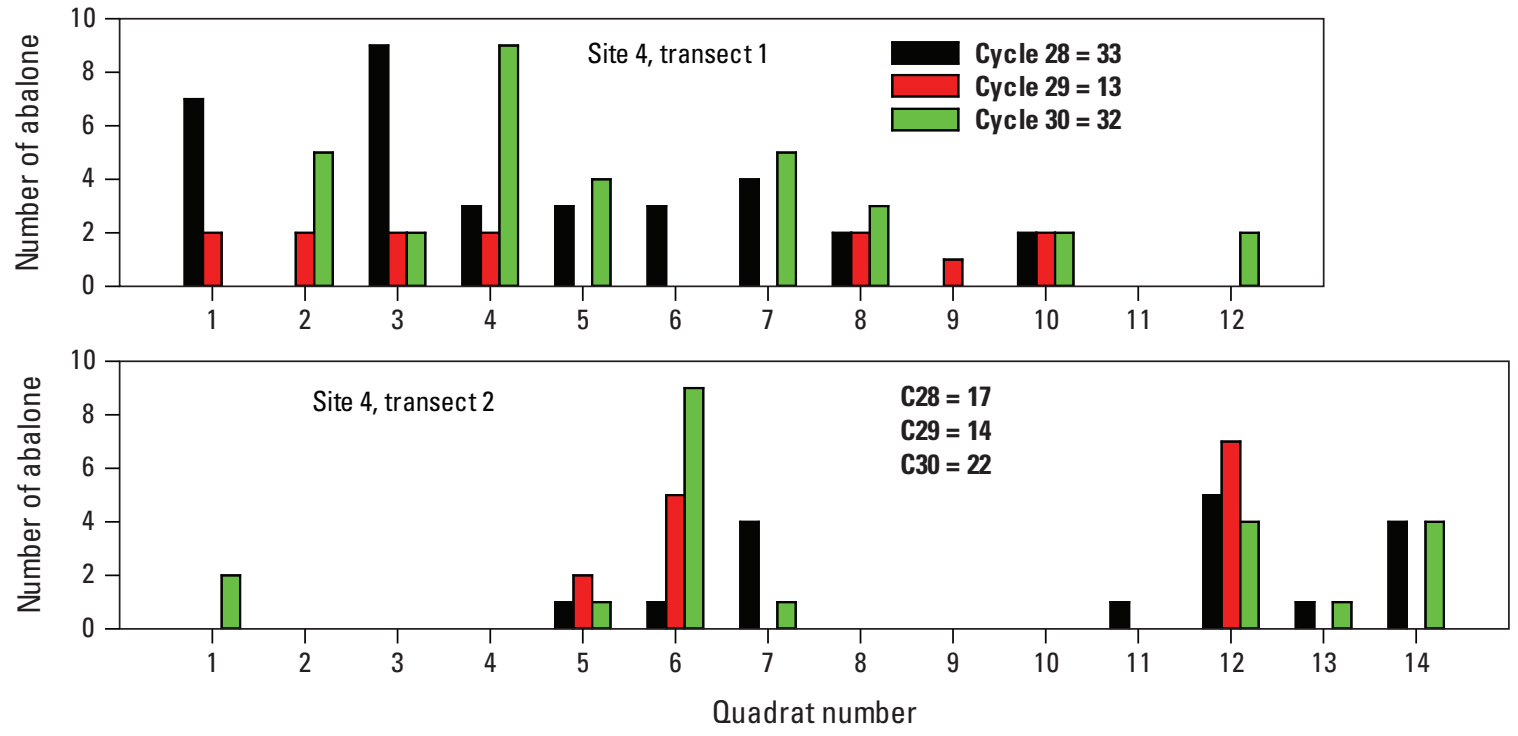

Figure 11. Cycle 28 (black bars), cycle 29 (red bars), and cycle 30 (green bars) distribution of black abalone along transects at site 4, San Nicolas Island, California, 2018-20. Total transect count for each cycle indicated on graph.
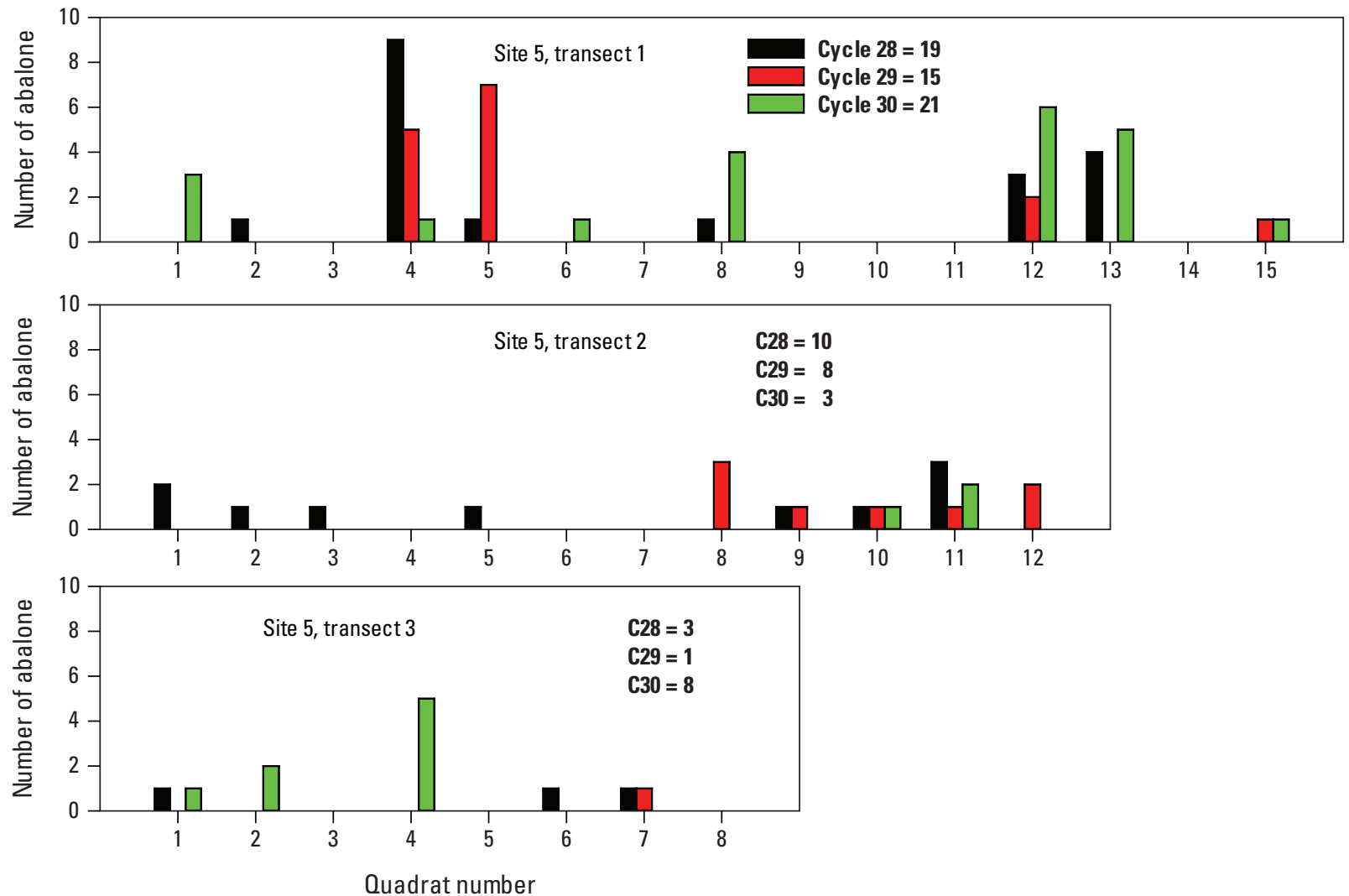

Figure 12. Cycle 28 (black bars), cycle 29 (red bars), and cycle 30 (green bars) distribution of black abalone along transects at site 5, San Nicolas Island, California, 2018-20. Total transect count for each cycle indicated on graph. 

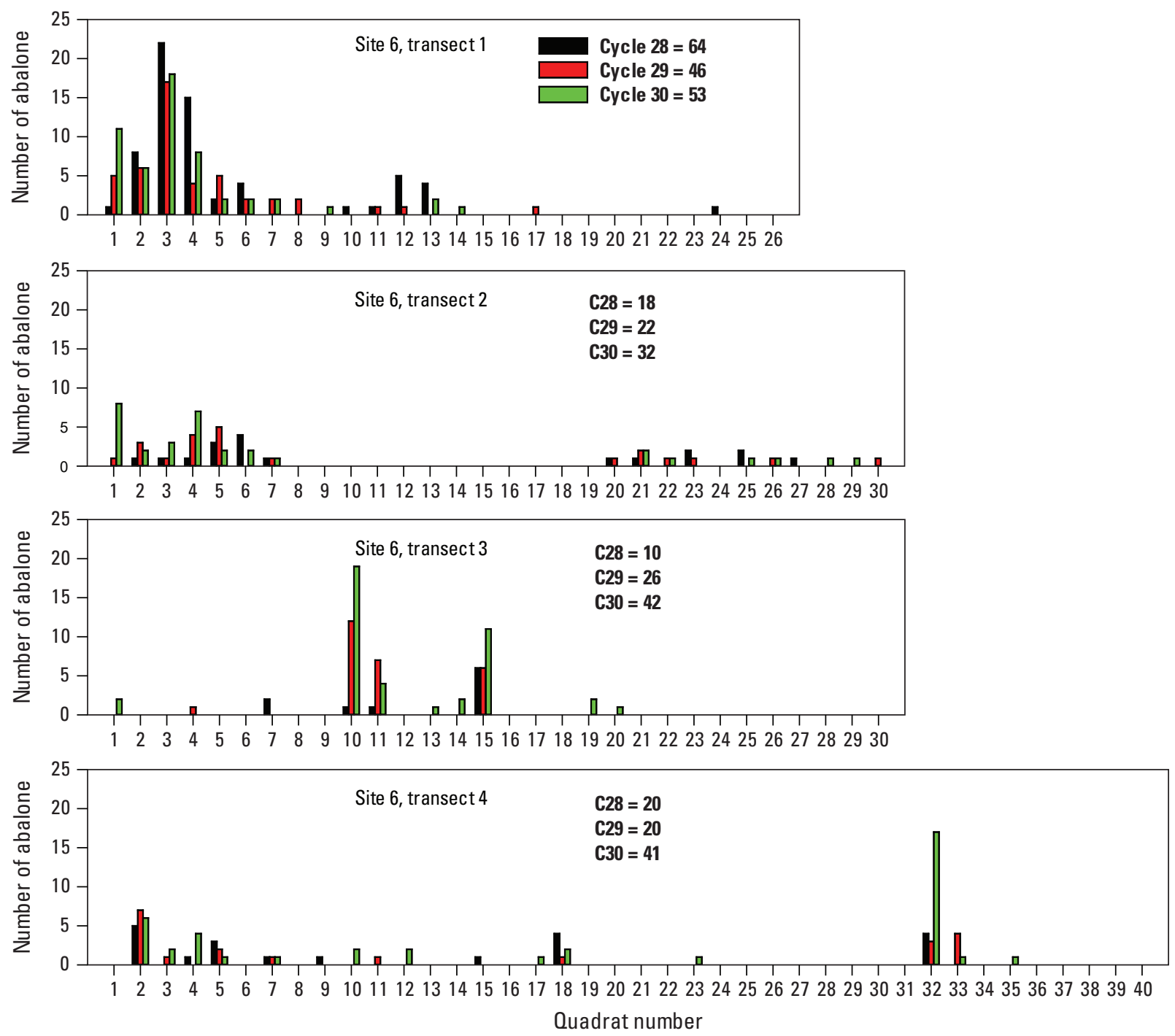

Figure 13. Cycle 28 (black bars), cycle 29 (red bars), and cycle 30 (green bars) distribution of black abalone along transects at site 6, San Nicolas Island, California, 2018-20. Total transect count for each cycle indicated on graph. 

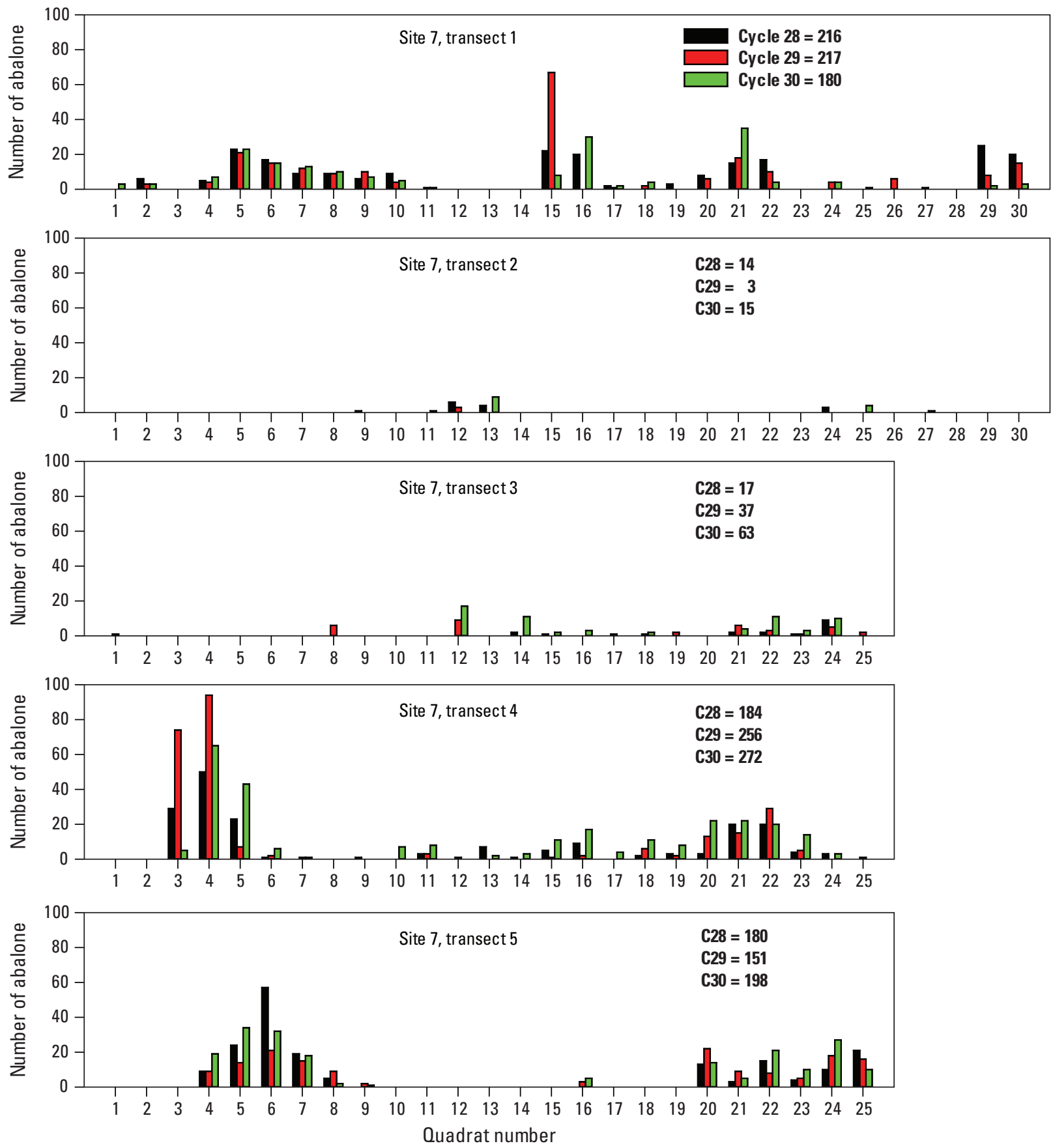

Figure 14. Cycle 28 (black bars), cycle 29 (red bars), and cycle 30 (green bars) distribution of black abalone along transects at site 7, San Nicolas Island, California, 2018-20. Total transect count for each cycle indicated on graph. 

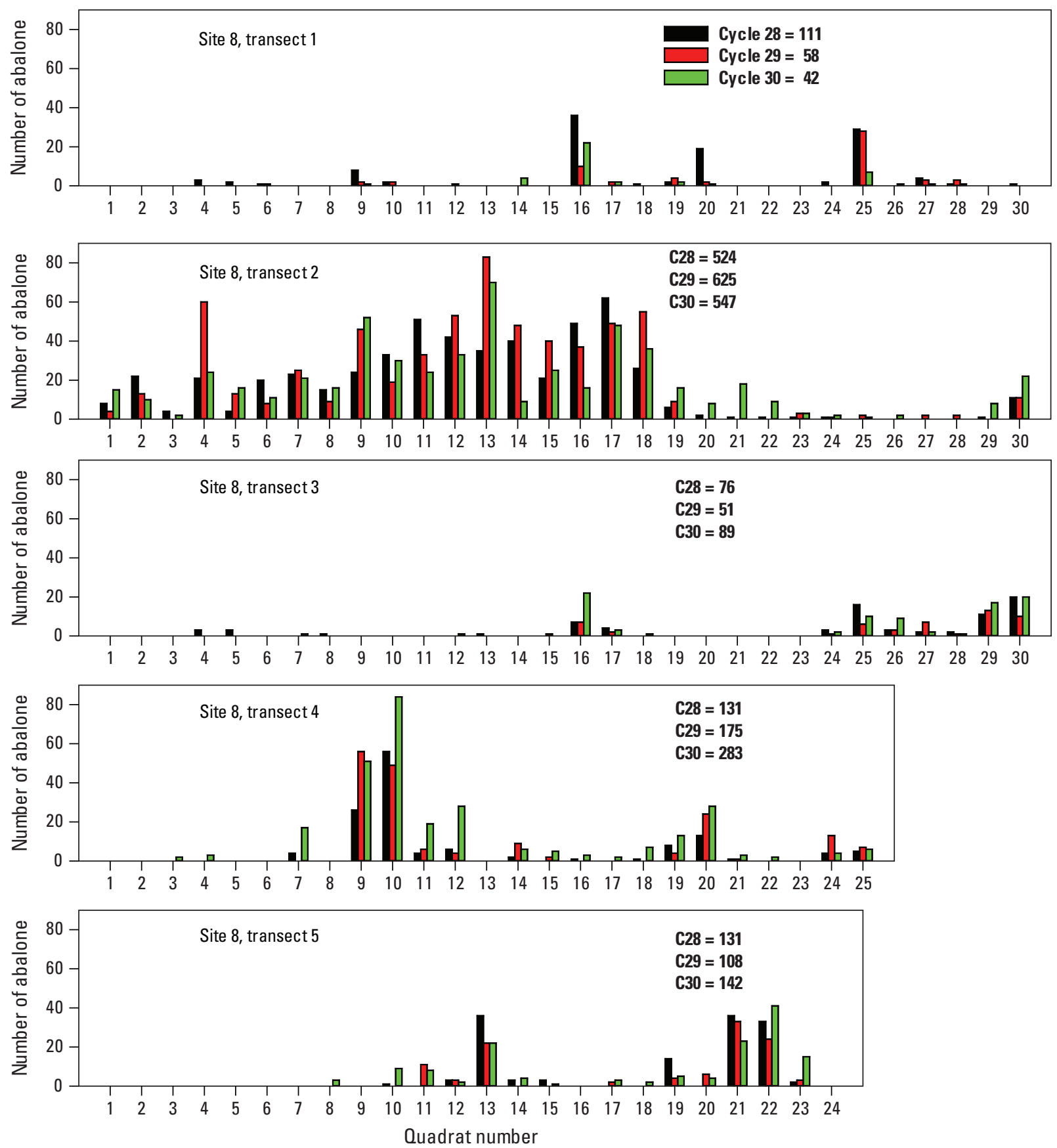

Figure 15. Cycle 28 (black bars), cycle 29 (red bars), and cycle 30 (green bars) distribution of black abalone along transects at site 8, San Nicolas Island, California, 2018-20. Total transect count for each cycle indicated on graph. 

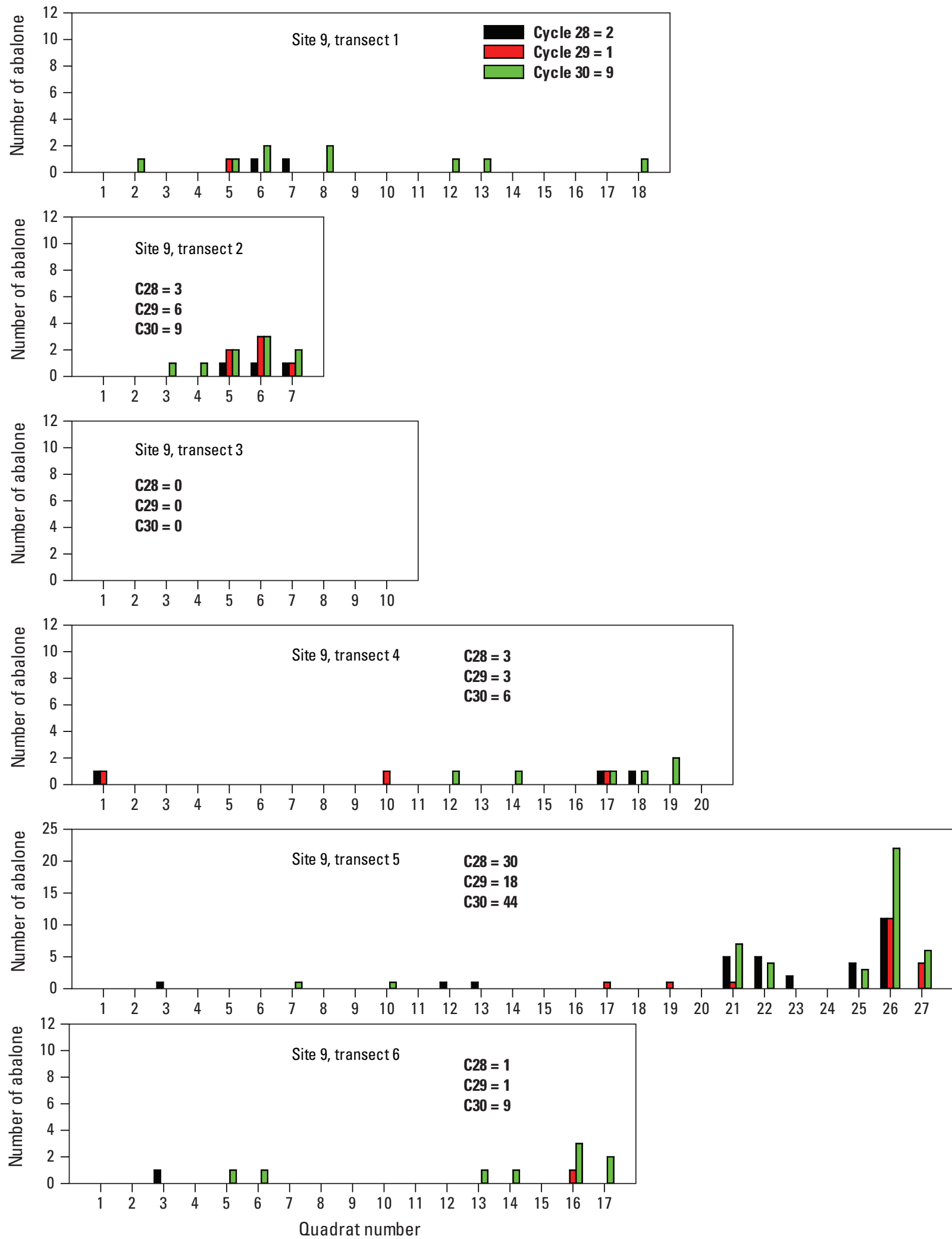

Figure 16. Cycle 28 (black bars), cycle 29 (red bars), and cycle 30 (green bars) distribution of black abalone along transects at site 9, San Nicolas Island, California, 2018-20. Total transect count for each cycle indicated on graph. 
Table 4. Distribution among microhabitats by site and transect, San Nicolas Island, California, 2020.

[Number of abalone observed in each microhabitat type. Transects with no abalone counted are not listed. Abbreviations: CR, Crevice; OH, Open horizontal; OV, Open vertical; \%, percent]

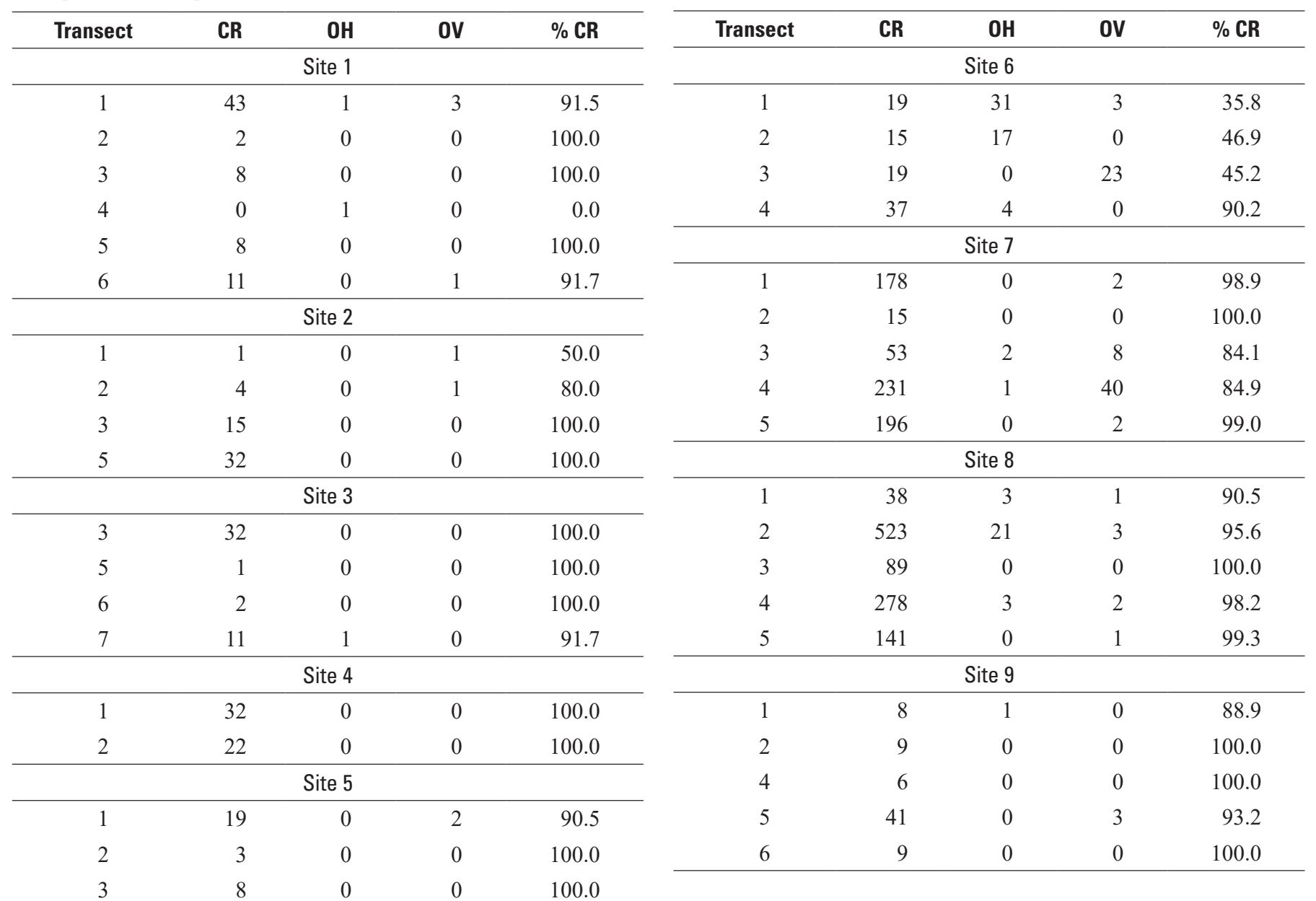




\section{Size Distribution and Recruitment}

Prior to WS reaching SNI in the early 1990s, the size distribution of black abalone at these sites was dominated by large adults (VanBlaricom, 1993). During the years 2001-20, the period after WS dramatically reduced the population, recruits began to become more common (fig. 17). This phenomenon, in concert with the dramatic reduction of the existing population, led to an obvious change in the overall shape of the size distribution. Of the 3,390 abalone measured prior to 1994 , only 20 were in the recruit size class ( 0.6 percent) and none of the samples from a site contained more than 4-percent recruits. This low level of recruitment contrasts with the whole island size samples from 2001 to 2020 when the percentage of recruits only fell below 5 percent twice and in the samples after 2007, the percentage of recruits was usually above 10 percent.

In 1988 (cycle 6), a size sample was acquired from all nine sites (G.R. VanBlaricom, unpub. data, 2019) and is used in this report for comparison with the more recent size structures. Because many of the recorded abalone could not be measured, there likely is some bias in the size data from the pre-WS years. The very high densities of adults at the time could have made juveniles much more difficult to see. This bias likely changed over time as abalone became much less crowded. Variability of bias in counts and measurements among sites and transects due to local topography also is likely. Figure 18 (top left panel) shows that most individuals, pre-WS, had shell lengths of $10-13 \mathrm{~cm}$. Proportionately, there were very few individuals $3 \mathrm{~cm}$ or less in length - the size range that, for practical purposes, is considered to be composed of recruits - and few small individuals in general. This lack of recruits is in contrast to the size distributions from 2001 onward (fig. 18, other panels). The size classes are much more evenly represented in the later years. Moreover, several of the recent years were dominated by smaller size classes. All of these samples show at least a few individuals in the recruitment size class. Recently settled abalone are thought to primarily inhabit cryptic habitat such as Mytilus beds or under boulders. As a result, individuals less than 2 or $3 \mathrm{~cm}$ likely are under-represented in size samples (VanBlaricom, 1993). The percent of the sample that is made up of these less than $3.5-\mathrm{cm}$ individuals is noted on each of the annual size plots.

There have been several large recruitment events in the last 10 years. A successful recruitment can shape the size distribution for several years as the mode composed of a young cohort moves across successive size plots. This phenomenon can be seen in the plots from 2010 to 2013. Based on the shape of the plot from 2002 to 2005, there was likely a larger recruitment in 2001 than is apparent in the data from that year.

The size frequency for each of the nine sites in 2019 and in 2020 is illustrated in figure 19. Six of the nine sites had some individuals in the recruitment cohort in 2019 , whereas eight of the nine had some in 2020. Sites 7 and 8 had the most individuals in this category in both years, but as a percentage of the local population, sites 8 and 5 continued to have the highest rate. Site 2, again, had the biggest proportion of individuals larger than $15 \mathrm{~cm}$. Table 5 shows numbers of recruits by site for each year from 2001 to 2020 . Sites 8 and 7 have contributed the most recruits over the years, followed by sites 5 and 3 .

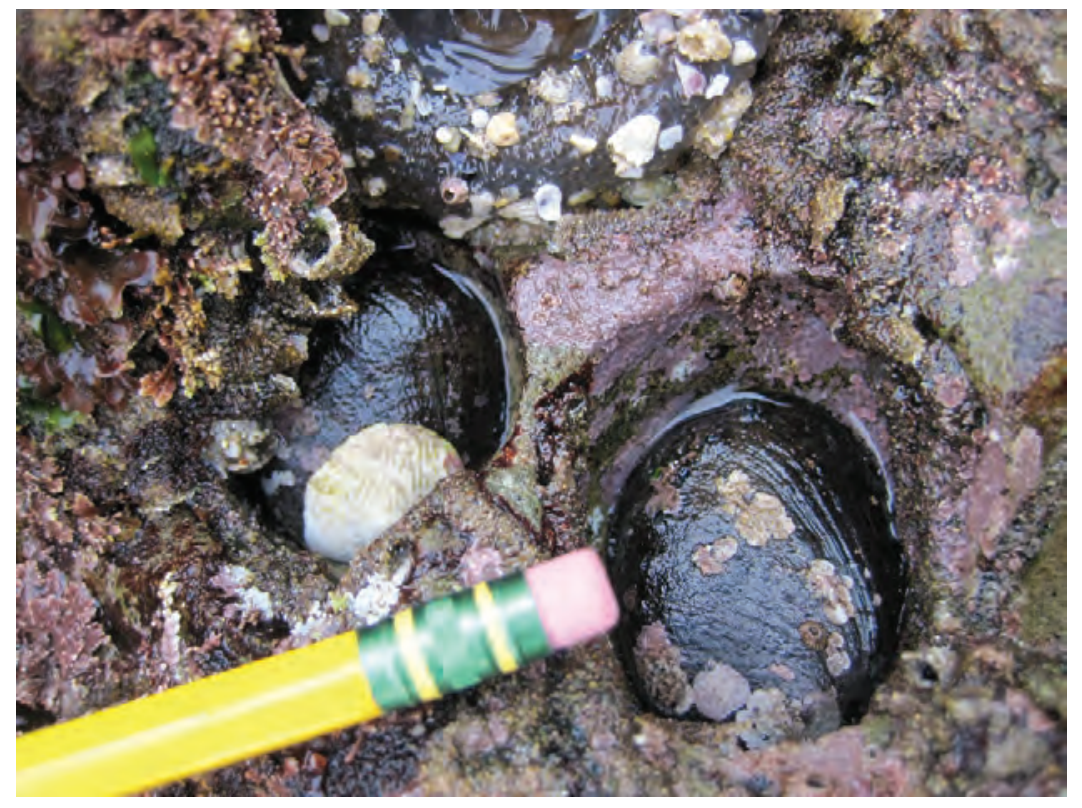

Figure 17. Two black abalone recruits at site 5-Shell length approximately 2 centimeters $(\mathrm{cm})$ in abandoned urchin cavity, San Nicolas Island, California. Photograph taken by M.C. Kenner, U.S. Geological Survey, January 1, 2018. 

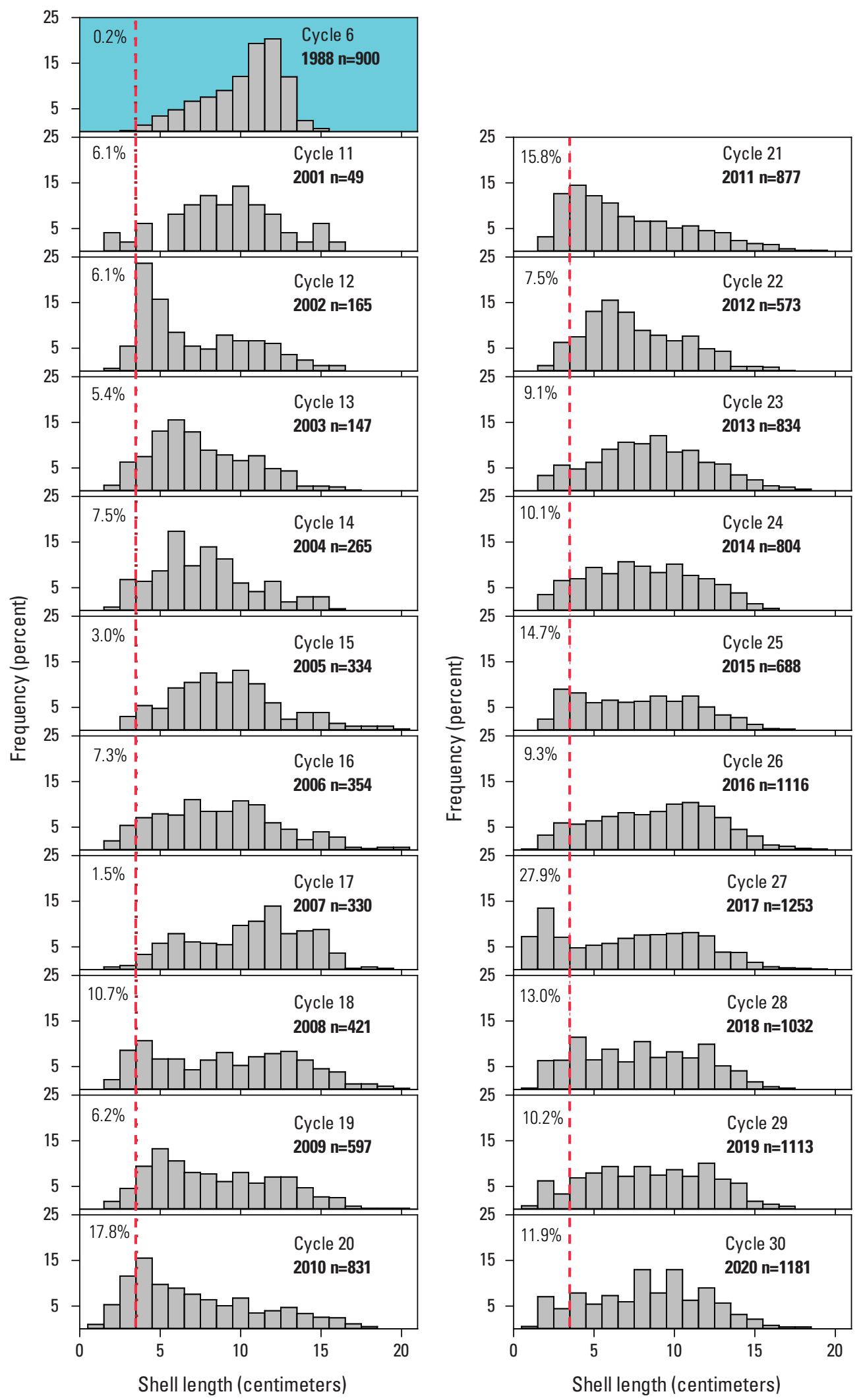

Figure 18. Whole island size distributions (total shell length in centimeters, $\mathrm{cm}$ ) of black abalone for 1988 (colored background) and 2001-20, San Nicolas Island, California. Sizes to the left of the dashed red line are considered recruits and the percentage of each sample in that category is indicated. 

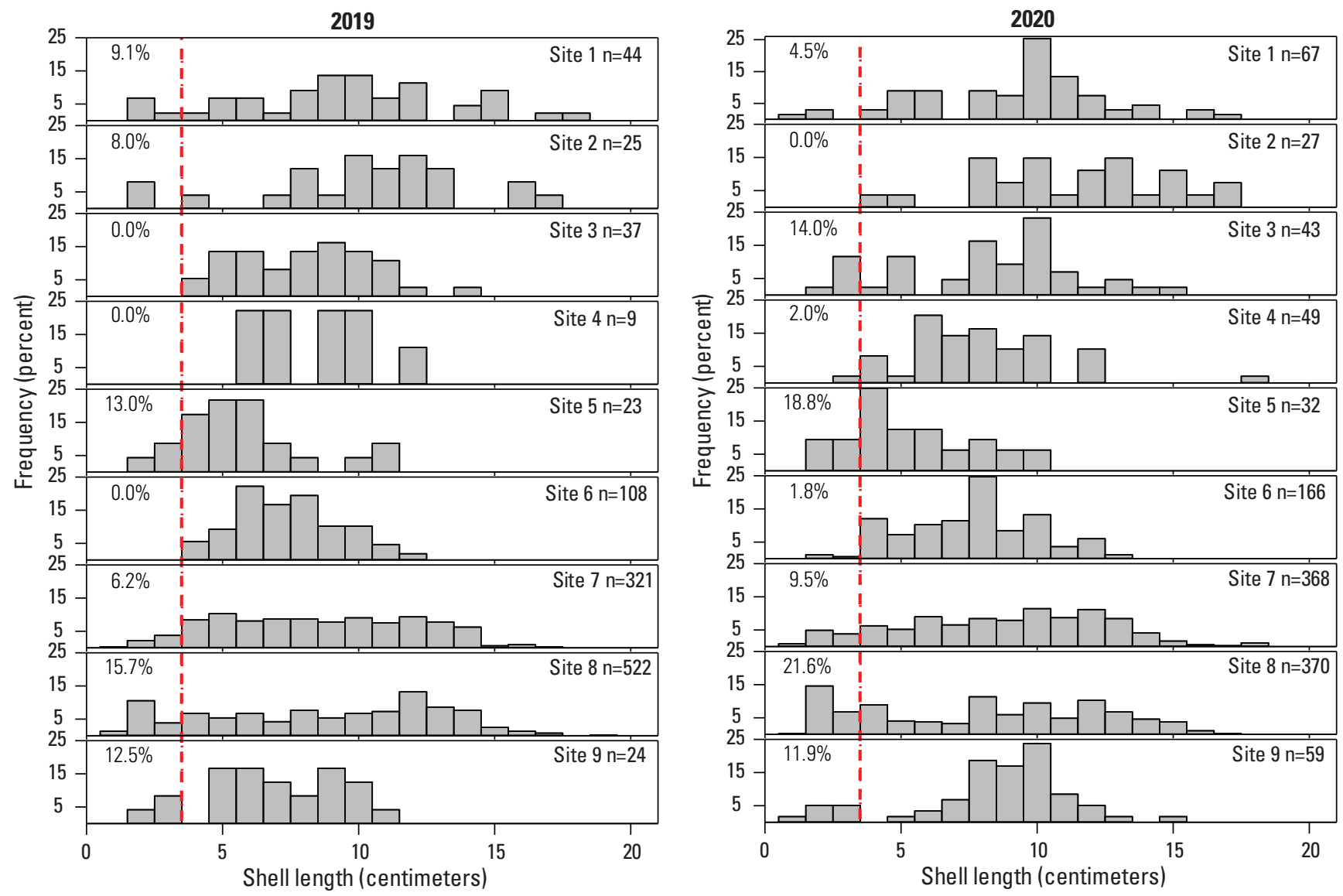

Figure 19. Size distribution (percentage frequency) of each site in 2019 (left) and 2020 (right), San Nicolas Island, California. Sizes to the left of the dashed red line are considered recruits and the percentage of each sample in that category is indicated.

A strong recruitment event was detected at site 8 , transects 1 and 2, in 2017. Figure 20 illustrates the sequence of size frequencies on these transects from 2016 to 2020. Note that the frequencies plotted are numbers of individuals rather than percentage of the sample and only represents the portion of the population on the transects that was measured, but the total number counted is indicated in the figure. Although the recruitment observed on transect 1 in 2017 increased total counts from 14 to 252 , there was only a net gain of 28 individuals (from 14 to 42 ) by 2020, even though there were additional recruits in subsequent years. The total number of recruits measured on transect 1 from 2017 to 2020 was 244 . On transect 2, total counts increased from 332 to 476 in 2017 and the net gain by 2019 was 293 abalone, although only 146 recruits were measured on this transect during the 3 years. By 2020, the net gain since 2017 dropped to 215 , despite the addition of 57 more measured recruits. The discrepancy between measured recruits and increase in count can be explained by the fact that, because of the complex structure of transect 2 , there were 484 unmeasured abalone in 2019 and 2020. Of these, 348 were estimated to be in the recruit size bin (table 5). It is likely there were similarly high numbers of unmeasured recruits in 2017 and 2018. There was considerable attrition of the new recruits, either from mortality or movement out of the transects, between 2017 and 2020. At one time (cycle 3), these two transects each had more than 1,300 abalone on them. 
Table 5. Number and percentage of measured abalone at each site that were recruits (less than 3.5 centimeters) for cycles 11-30 (2001-20) and total recruits for each cycle, San Nicolas Island, California.

[Values in parenthesis () indicate percent. Bottom rows show numbers of non-measured abalone estimated to be in the recruit size bin in cycle 29 and 30 and as a percentage of sized abalone - either measured or estimated into size bins—-for those cycles (see "Methods" section). Abbreviation: NR, not recorded]

\begin{tabular}{|c|c|c|c|c|c|c|c|c|c|c|c|}
\hline \multirow{2}{*}{ Cycle } & \multirow{2}{*}{ Year } & \multicolumn{9}{|c|}{ Site } & \multirow{2}{*}{ All sites } \\
\hline & & 1 & 2 & 3 & 4 & 5 & 6 & 7 & 8 & 9 & \\
\hline 11 & 2001 & 0 & 0 & 0 & 0 & 0 & 0 & 0 & $3(10.0)$ & 0 & $3(6.1)$ \\
\hline 12 & 2002 & $1(10.0)$ & 0 & 0 & 0 & 0 & 0 & 0 & $9(9.2)$ & 0 & $10(6.1)$ \\
\hline 13 & 2003 & 0 & 0 & $5(29.4)$ & 0 & $2(8.0)$ & 0 & 0 & 0 & $1(8.3)$ & $8(5.4)$ \\
\hline 14 & 2004 & 0 & 0 & $4(7.8)$ & 0 & 0 & $1(11.1)$ & $4(9.3)$ & $11(8.5)$ & 0 & $20(7.5)$ \\
\hline 15 & 2005 & 0 & 0 & $4(11.8)$ & 0 & $3(10.3)$ & 0 & 0 & $3(1.5)$ & 0 & $10(3.0)$ \\
\hline 16 & 2006 & 0 & 0 & $2(8.3)$ & 0 & $8(23.5)$ & 0 & $1(2.0)$ & $15(6.9)$ & 0 & $26(7.3)$ \\
\hline 17 & 2007 & 0 & 0 & $1(5.3)$ & 0 & 0 & 0 & $1(3.2)$ & $3(1.3)$ & 0 & $5(1.5)$ \\
\hline 18 & 2008 & 0 & 0 & $14(33.3)$ & 0 & $11(16.9)$ & 0 & $2(4.2)$ & $18(7.4)$ & 0 & 45 (10.7) \\
\hline 19 & 2009 & 0 & $1(12.5)$ & $13(14.3)$ & 0 & $13(24.1)$ & 0 & $1(1.4)$ & $9(2.6)$ & 0 & $37(6.2)$ \\
\hline 20 & 2010 & $3(14.3)$ & $2(20.0)$ & $10(14.7)$ & $2(16.7)$ & $17(28.3)$ & $1(11.1)$ & $42(24.6)$ & $70(15.1)$ & $1(6.7)$ & $148(17.8)$ \\
\hline 21 & 2011 & $2(8.7)$ & $5(33.3)$ & $9(11.8)$ & $1(6.7)$ & $12(21.1)$ & 0 & $16(10.6)$ & $92(18.6)$ & $2(7.4)$ & $139(15.8)$ \\
\hline 22 & 2012 & $2(10.0)$ & $6(25.0)$ & $3(3.9)$ & 0 & $5(8.8)$ & 0 & $15(7.8)$ & $11(8.1)$ & $1(3.4)$ & $43(7.5)$ \\
\hline 23 & 2013 & 0 & 0 & $8(8.8)$ & 0 & $15(37.5)$ & 0 & $48(13.2)$ & $5(2.0)$ & 0 & $76(9.1)$ \\
\hline 24 & 2014 & $5(12.5)$ & $3(14.3)$ & $8(11.1)$ & $2(6.1)$ & $6(25.0)$ & 0 & $30(8.2)$ & $27(13.6)$ & 0 & $81(10.1)$ \\
\hline 25 & 2015 & $4(6.6)$ & $1(4.5)$ & $16(17.0)$ & 0 & $6(37.5)$ & $1(3.2)$ & $36(16.7)$ & $35(17.2)$ & $2(6.3)$ & $101(14.7)$ \\
\hline 26 & 2016 & $3(8.3)$ & $6(26.1)$ & 0 & $3(8.1)$ & $6(25.0)$ & $4(8.7)$ & $64(16.9)$ & $9(1.7)$ & $9(30.0)$ & $104(9.3)$ \\
\hline 27 & 2017 & $14(33.3)$ & 0 & $8(14.3)$ & $3(6.4)$ & $14(43.8)$ & $6(10.2)$ & $35(17.5)$ & $247(32.8)$ & $22(50.0)$ & 349 (27.9) \\
\hline 28 & 2018 & $4(6.3)$ & $1(3.1)$ & $1(2.1)$ & $2(4.9)$ & $1(3.2)$ & $7(6.6)$ & $18(8.7)$ & $100(21.5)$ & 0 & $134(13.0)$ \\
\hline 29 & 2019 & $4(9.1)$ & $2(8.0)$ & 0 & 0 & $3(13.0)$ & 0 & $20(6.2)$ & $82(15.7)$ & $3(12.5)$ & $114(10.2)$ \\
\hline 30 & 2020 & $3(4.5)$ & 0 & $6(14.0)$ & $1(2.0)$ & $6(18.8)$ & $3(1.8)$ & $35(9.5)$ & 80 (21.6) & 7 (11.9) & $141(11.9)$ \\
\hline Cycle 29 estim & & 3 & 3 & 0 & 0 & 0 & 0 & 37 & 125 & NR & 168 \\
\hline \multicolumn{2}{|c|}{ Cycle 29 percent including estimated sizes } & $(10.1)$ & $(13.5)$ & $(0.0)$ & $(0.0)$ & $(12.5)$ & $(0.0)$ & $(9.1)$ & $(20.5)$ & NR & $(14.4)$ \\
\hline \multicolumn{2}{|c|}{ Cycle 30 estimated } & 0 & 2 & 1 & 0 & 0 & 0 & 74 & 223 & 4 & 304 \\
\hline \multicolumn{2}{|c|}{ Cycle 30 percent including estimated sizes } & $(4.0)$ & $(3.7)$ & $(12.8)$ & $(1.9)$ & $(18.8)$ & $(1.8)$ & $(15.0)$ & $(27.5)$ & $(14.3)$ & $(19.0)$ \\
\hline
\end{tabular}


Site 8, transect 1

Site 8, transect 2

Cycle 26 (2016)

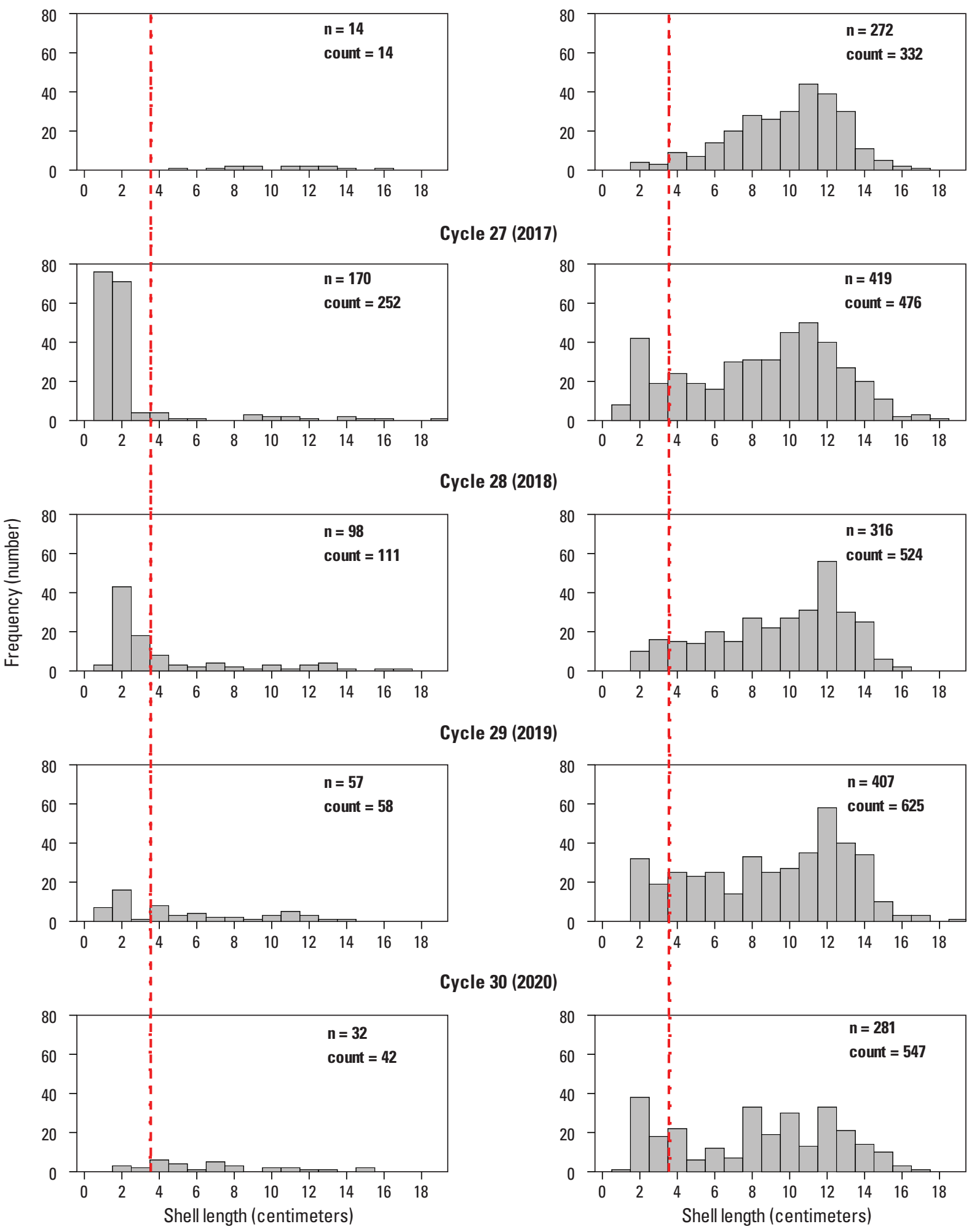

Figure 20. Recruitment pulse as observed in the size distribution measured in 2016-20 at site 8, transects 1 (left) and 2 (right), San Nicolas Island, California. Frequencies are presented here as numbers rather than percentage of sample size. Sizes to the left of the dashed red lines may be considered recruits ( $\mathrm{n}$ is measured sample size; count is total count on transect). 


\section{Nearest Neighbors}

The mean nearest neighbor distance has been declining over several years as the population size has increased. Figure 21 shows this trend since 2005 when consistent efforts were first made to measure this parameter. Also, plotted are the percentage of each sample within $10 \mathrm{~cm}$ and within $100 \mathrm{~cm}$ of the nearest conspecific. The trend for all three metrics is toward closer proximity, and in 2020, more than 97 percent of the sampled abalone were within 1 meter of another.

Figure 22 shows nearest neighbor distance bins plotted by site for 2020 . Sites 7 and 8 , which dominate in terms of total abalone count, also drive the high numbers toward close proximity. These two sites contained 78.2 percent of the counted population, and 89.4 percent of these 1,831 abalone were within $10 \mathrm{~cm}$ of another black abalone. In general, the other sites are fairly evenly spread among the bins, with only 51.8 (range of 40.6-67.9) percent of the counted abalone within $10 \mathrm{~cm}$ of another.

Table 6 shows the nearest neighbor distance bins assigned to measured abalone that were in the recruit size classes (less than $3.5 \mathrm{~cm}$ ) for each year from 2005 to 2020 . Most recruits, like their adult counterparts, are found in the first and second bins, between 0 and $10 \mathrm{~cm}$ from other abalone.

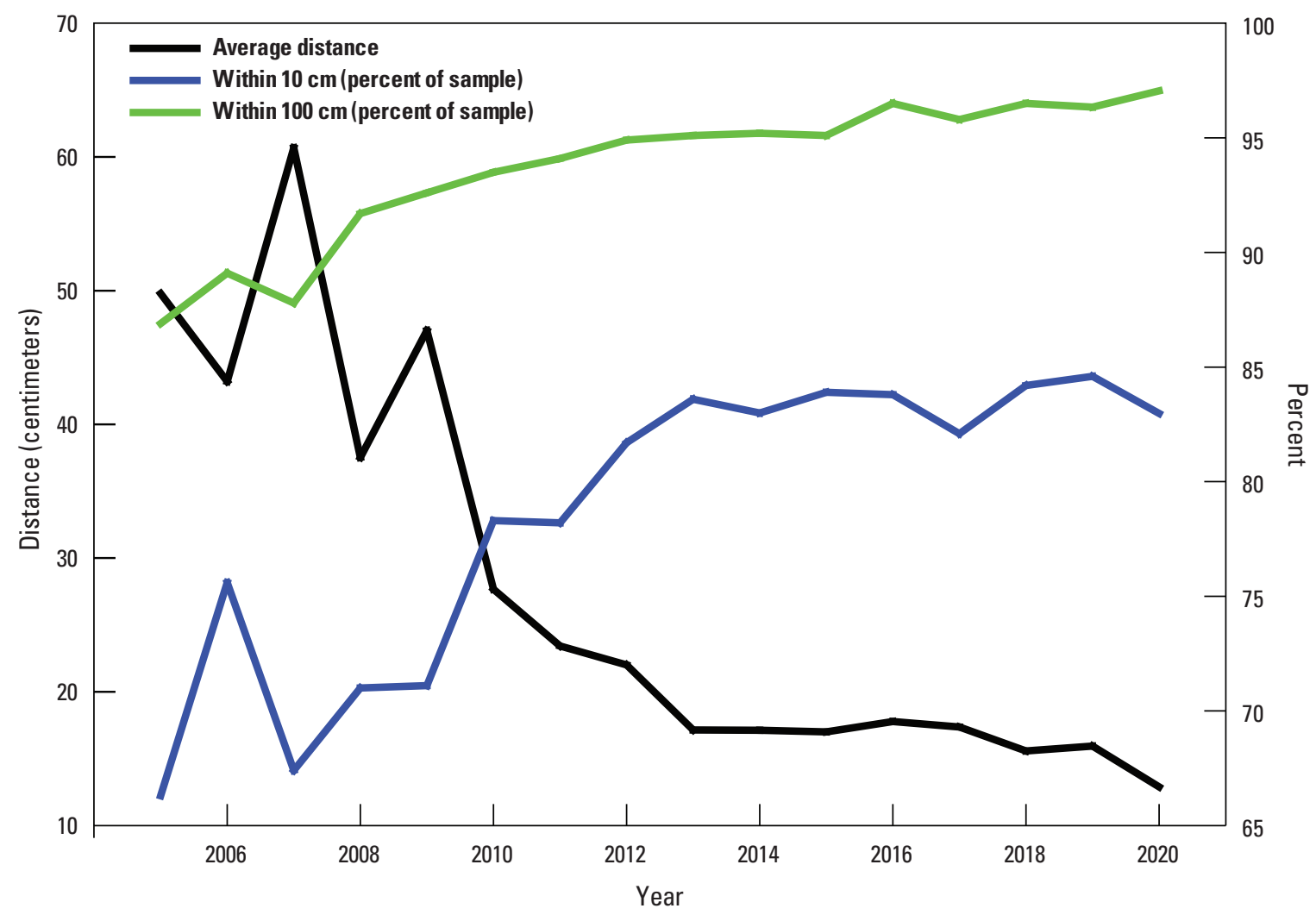

Figure 21. Mean nearest neighbor distance in 2005-20 and percentage of sample within 10 centimeters $(\mathrm{cm})$ and within $100 \mathrm{~cm}$ of neighbor, San Nicolas Island, California. 


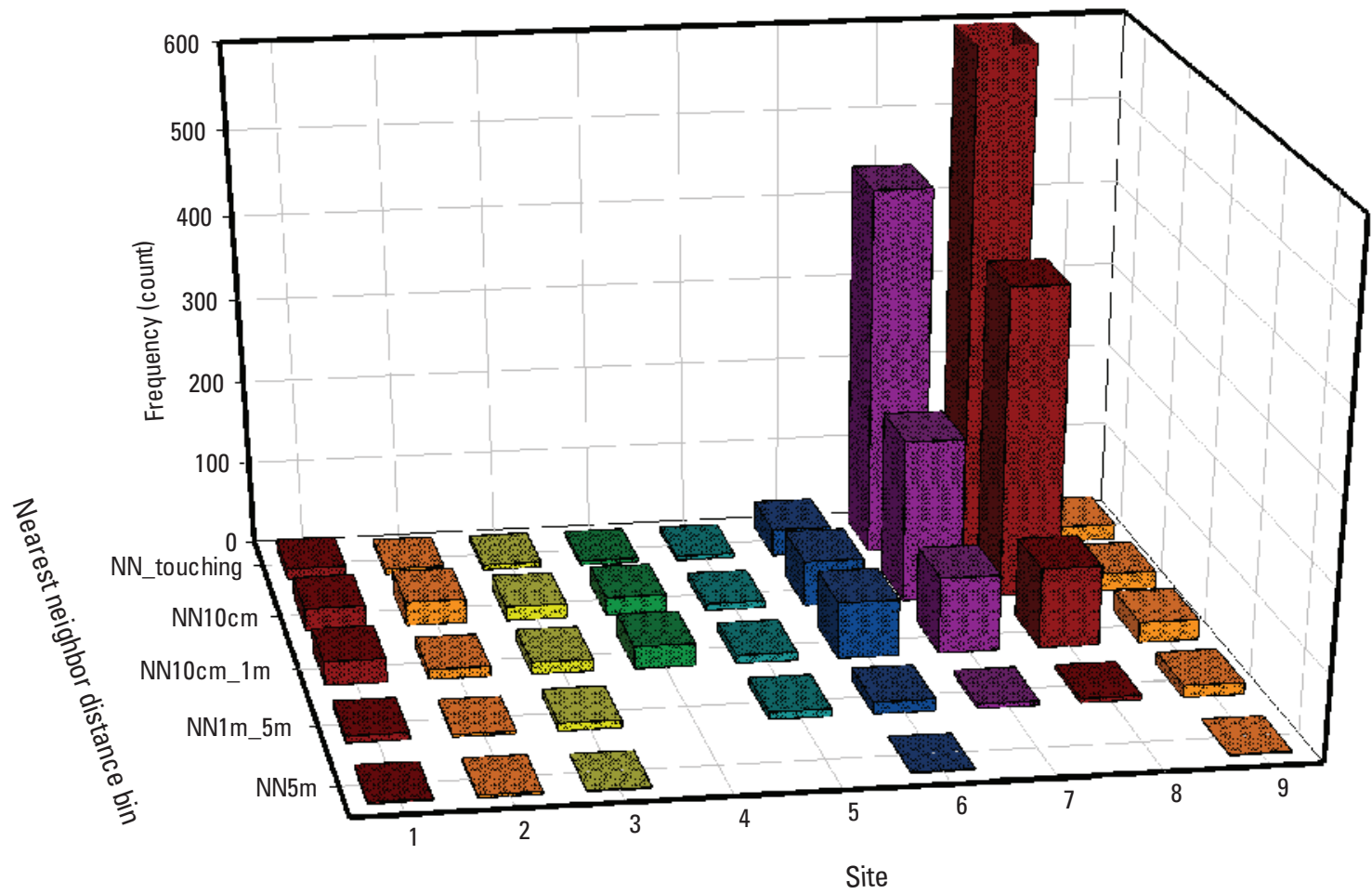

Figure 22. Nearest neighbor (NN) distance bins by site for 2020, San Nicolas Island, California. The bins are "NN touching" less than 1 centimeter $(\mathrm{cm})$, "NN10cm" =1-10 cm, “NN10cm_1 meter $(\mathrm{m})$ " =11 cm-1 m, “NN1m_5m" =1.01-5 m, and “NN5m" more than $5 \mathrm{~m}$.

Table 6. Total recruits for cycles 15-30 (2005-20) by nearest neighbor distance bin, San Nicolas Island, California.

[Percent of total (not recorded [NR] excluded) at bottom. Recruits defined as measured individuals with a shell length less than 3.5 centimeters (cm). Abbreviations: m, meter; >, greater than]

\begin{tabular}{|c|c|c|c|c|c|c|c|}
\hline \multirow{2}{*}{ Cycle } & \multirow{2}{*}{ Year } & \multicolumn{6}{|c|}{ Nearest neighbor bins } \\
\hline & & NR & $0 \mathrm{~cm}$ & $1-10 \mathrm{~cm}$ & $11 \mathrm{~cm}-1 \mathrm{~m}$ & $1-5 \mathrm{~m}$ & $>5 \mathrm{~m}$ \\
\hline 15 & 2005 & 0 & 1 & 1 & 8 & 0 & 0 \\
\hline 16 & 2006 & 7 & 3 & 13 & 2 & 1 & 0 \\
\hline 17 & 2007 & 0 & 3 & 0 & 2 & 0 & 0 \\
\hline 18 & 2008 & 0 & 11 & 19 & 12 & 3 & 0 \\
\hline 19 & 2009 & 0 & 10 & 17 & 8 & 2 & 0 \\
\hline 20 & 2010 & 1 & 56 & 66 & 20 & 5 & 0 \\
\hline 21 & 2011 & 1 & 78 & 35 & 16 & 8 & 1 \\
\hline 22 & 2012 & 1 & 14 & 10 & 13 & 3 & 2 \\
\hline 23 & 2013 & 0 & 29 & 27 & 16 & 4 & 0 \\
\hline 24 & 2014 & 0 & 36 & 26 & 14 & 4 & 1 \\
\hline 25 & 2015 & 0 & 48 & 34 & 10 & 9 & 0 \\
\hline 26 & 2016 & 2 & 51 & 39 & 8 & 3 & 1 \\
\hline 27 & 2017 & 2 & 133 & 133 & 64 & 14 & 3 \\
\hline 28 & 2018 & 0 & 75 & 39 & 16 & 4 & 0 \\
\hline 29 & 2019 & 0 & 70 & 26 & 14 & 3 & 1 \\
\hline 30 & 2020 & 0 & 71 & 38 & 28 & 4 & 0 \\
\hline \multicolumn{3}{|c|}{ Total for all cycles } & 689 & 523 & 251 & 67 & 9 \\
\hline \multicolumn{3}{|c|}{ Percent for all cycles } & 44.8 & 34.0 & 16.3 & 4.4 & 0.6 \\
\hline
\end{tabular}




\section{Sedimentation}

There is not a clear relationship between sand cover estimated in quadrats and abalone counts. Statistical tests of correlations between sand cover and abalone counts and between change in sand cover and change in abalone counts were not significant. Sand cover in the quadrats did not exhibit an obvious trend temporally or by transect. Figure 23 shows mean sand cover for selected transects (those with generally higher cover) and total mean sand cover, over time, from 2001 to 2020. Although there could be a weak increasing trend overall, it is clear that inter-year and inter-transect variation are more important. There appears to be only weak synchrony between the transects although, in 2016, several appeared to peak in sand cover. Ironically, for the one case where it is thought that sand burial caused mass mortality of black abalone (decline recorded winter 2016, site 3, transects 1 and 2 ), there was no sand cover in the data. The sand cover there was apparently brief and catastrophic and could have resulted from a temporary change, observed in October 2015, in the size and shape of the sand spit on the east end of the island. The sites more typically influenced by sand are 1, 7, and 8 .

How sand cover affects abalone is likely to be a result of several factors, including depth of burial, duration of the event, and the availability of protruding rock refugia. An example is site 7, transect 4, where total abalone counts increased by 16 between 2019 and 2020 despite increasing sand cover and within-quadrat abalone declines of as much as 70 (quadrat 3 east) and 42 (quadrat 4 west). Figure 24 shows that the increase in sand cover was uneven, and there was a shift in abalone abundance out of quadrats 3 and 4 toward 5 and 6 as well as increases in several quadrats further along the transect. It appears that abalone were able to move away from sand burial. The number of abalone in the open vertical microhabitat category increased from 13 to 40 as some literally climbed the walls to escape the sand. In contrast, the transects at site 3 , that suffered heavy mortality in 2015, are relatively flat benchtops, lacking vertical refugia.

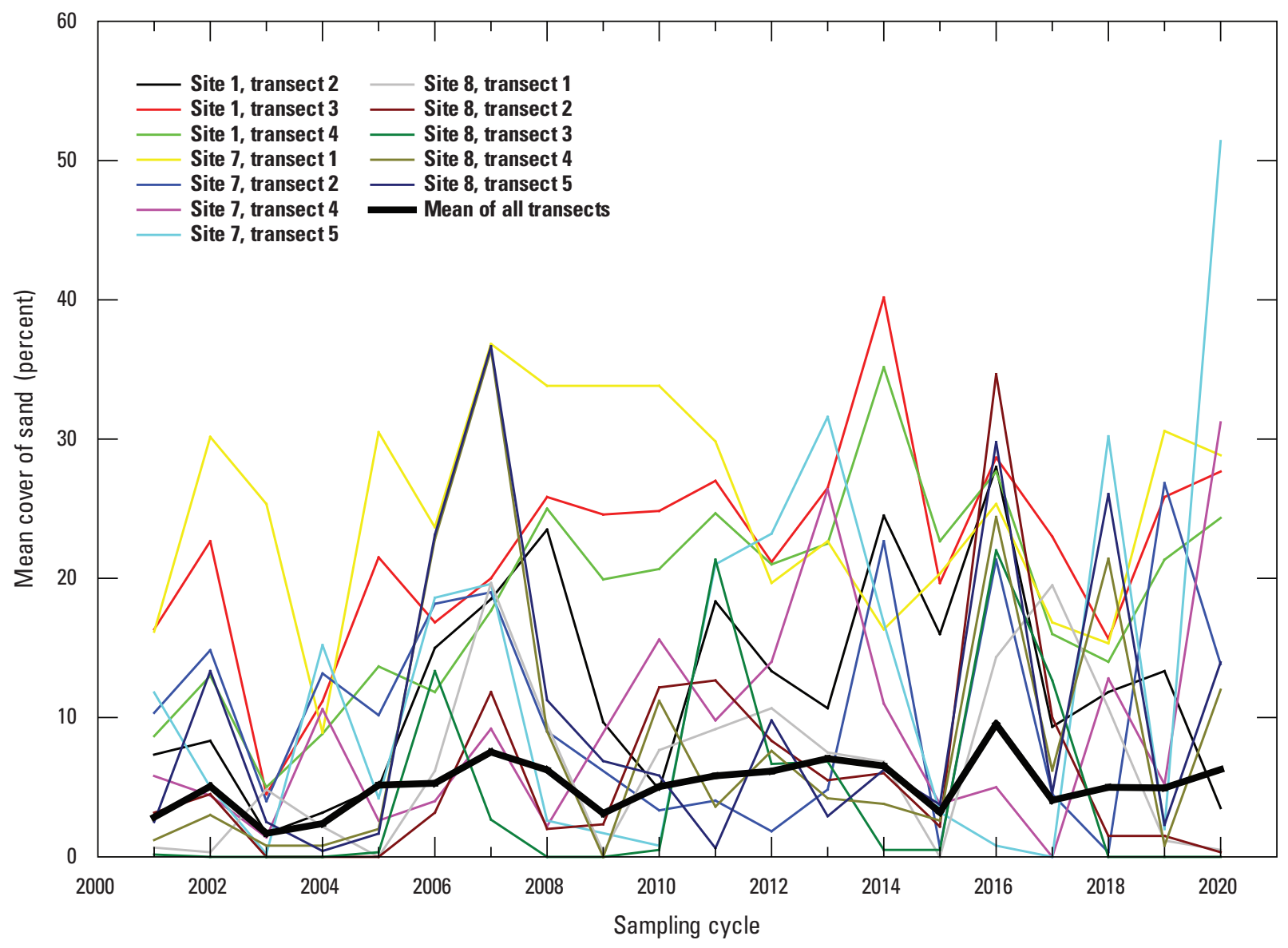

Figure 23. Average sand cover on selected transects for 2001-20, San Nicolas Island, California. Heavy black line shows total mean cover over time. 


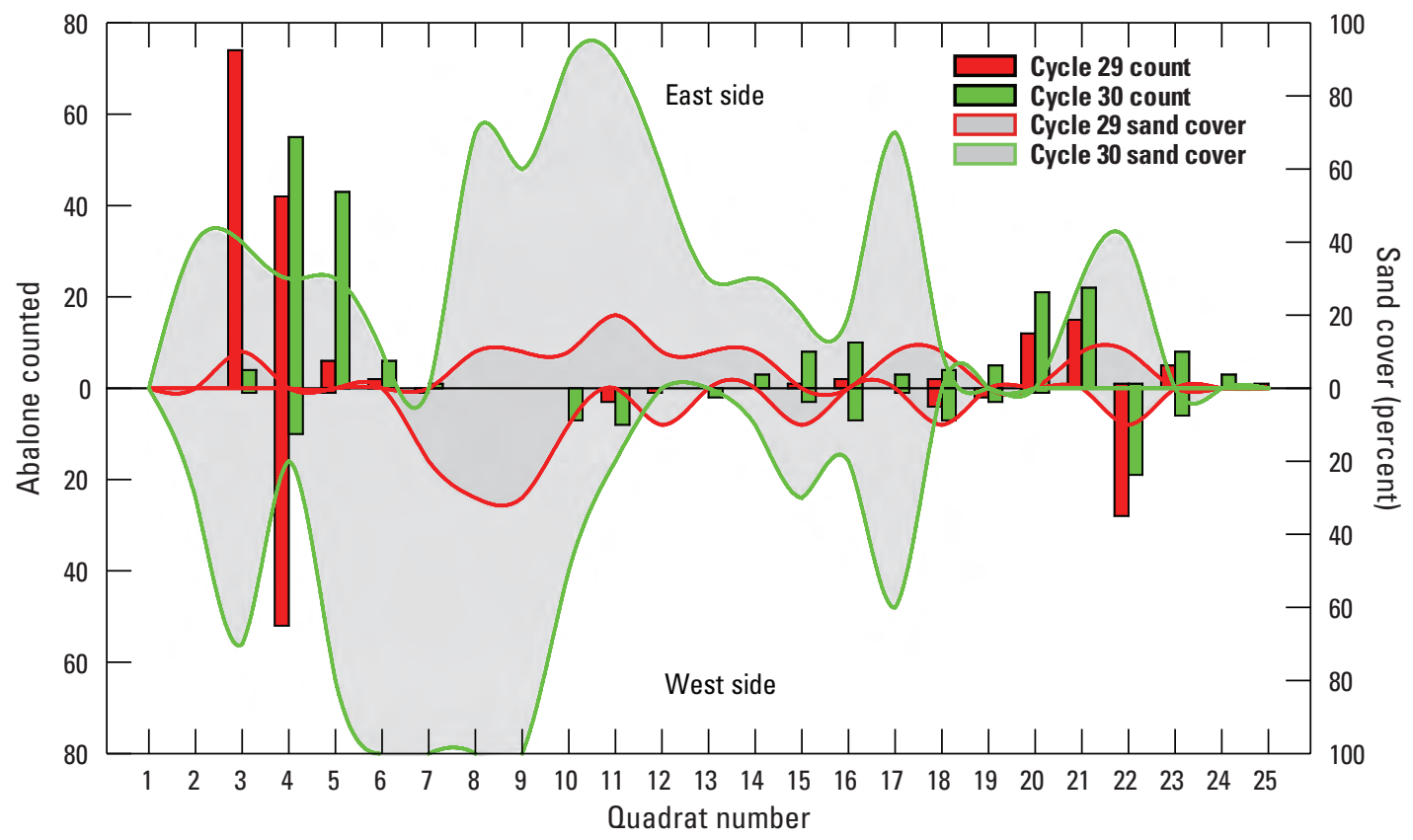

Figure 24. Abalone counts and sand cover by quadrat for site 7, transect 4 in cycle 29 and cycle 30, San Nicolas Island, California.

\section{Discussion and Conclusions}

Following 3 years of near static counts, there was a considerable increase in the total black abalone counted on the monitoring transects at SNI in 2020. It is not clear what led to this gain of 319 abalone. Counts increased at all sites, although there were declines on 9 of the 42 transects (as much as 78 abalone on site 8 , transect 2) and no change on 8 transects. Most of the increase in abalone was at sites 6,7, 8 , and 9 and ranged from 48 to 86 at these sites. The overall recruitment rate, based on measured abalone less than $3.5 \mathrm{~cm}$, was 11.9 percent in 2020 , which is slightly less than the average of 13.5 percent for the previous 10 years. At site 6 , in particular, the increase in the count by 47.4 percent could not be explained by the low recruitment rate there (1.8 percent). Although a higher recruitment rate was calculated for some of the sites using the non-measured, estimated recruits (table 5), that rate cannot be compared to earlier cycles because it is a newer protocol. It is likely that the increase in counts in 2020 resulted, in part, from animals that moved into the transects from adjacent areas, and it is not yet clear whether these increasing transect counts reflect overall population increases.

Most black abalone recruits were found in close proximity (within $10 \mathrm{~cm}$ ) to conspecifics. Whether this pattern is a result of settlement cues or some other phenomenon, such as migration or differential survival, is unclear, but this apparent intra-species fidelity, though favorable in the long-term for spawning success, could tend to limit resettlement of unoccupied areas. Likely resulting from this uneven distribution of recruits, a similar pattern is seen in the larger size classes, suggesting that, though there is evidence of abalone movement, there is not an inclination toward adult dispersal.

The cycle 26 count from 2016 fell considerably below the apparent trend for growth of the population during the last 20 years that is shown in the GAM curve in figure 4. That count was 10.5-percent less than the previous total and furthest outside the 95-percent confidence band, demonstrating its deviance from the trend. An examination of the 2016 counts in table 3 reveals that most of the decline occurred at sites 3 and 8 . Site 3, as mentioned in the "Sites" section, suffered an apparent sand inundation event in fall 2015 that reduced the abalone count to zero on transects 1 and 2, resulting in a decline of 49 individuals compared to the previous year, and there was an overall decline of 96 for the whole site. No abalone have yet returned to these two transects. Most of the decline of 213 abalone that occurred at site 8 resulted from losses on transect 2 of 28.9 percent (a reduction of 135 abalone) and losses on transect 5 of 47.2 percent (a reduction of 68 abalone). The cause of these site 8 declines is not clear, but there was a reduction in juvenile and small abalone on transect 2, with the percentage of measured abalone $5 \mathrm{~cm}$ or less in length, dropping from 25 to 8.5 percent. Apparently, the potential mortality or movement of abalone out of the transects affected these smaller sizes disproportionally. On transect 5, sand cover increased from a mean of 3.8 to 29.8 percent with cover increasing in 30 of the 48 quadrats and only decreasing in 1 . At the same time, the abalone on open vertical microhabitat increased from 0.7 to 16.2 percent. It seems likely that, like site 3 , the losses on this transect were sand related. 
Aside from the unusual sand burial event that occurred in 2015, at site 3 , the sites with the most sand influence were sites 1,7 , and 8 . These sites had large deposits of loose sand shoreward, in addition to offshore sources. The sites all had large sea lion haul-outs as well. Site 1, in particular, has undergone noticeable coastal degradation during the last few decades, apparently as a direct result of the increasing California sea lion population using the area. Sea lion use of the west end of SNI, including site 1, increased dramatically in the mid-1990s and substantial seaside terrestrial erosion has occurred since that time. It is not clear to what extent proximal sand is a detriment to the abalone population, but it is apparent that sand burial can cause mortality.

There are several positive signs for the black abalone population at SNI. The monitored population size is almost 10 percent of the pre-WS average, which is up from less than 1 percent in 2001. Some detectable recruitment has occurred every year since then, and the counts at all sites have increased. This year (2020), in particular, counts at all sites went up, with four of the nine sites increasing nearly 50 percent or more from the previous year. There are now three sites with average densities above 1 per $\mathrm{m}^{2}$. In addition, nearest neighbor distances have continued to decline, presumably improving the odds for successful spawning events.

There are negatives that should temper optimism, however. Much of the apparent population growth this year likely came from movement into transects from adjacent areas rather than from new recruits to the island population. Nearly half the sampled population still resides at just one of the nine sites. Factors leading to higher recruitment levels are not yet understood, and these could be short-term phenomena relating to fluctuating oceanographic conditions or other factors. Although it appears that some SNI abalone might have gained resistance to the effects of WS (Friedman and others, 2014), a return of the disease could still have a significant impact on the remaining population. Finally, stochastic disturbance events beyond human control, such as storm damage or sand burial, could take a toll on small populations.

The results of this study apprise managers of the status of the black abalone population at SNI and provide information to assist in decision making. Afforded the clean offshore water and abundant standing stock of kelp that SNI provides, this population, likewise benefitting from limited island access and strict environmental controls, is thus far one of the most promising for black abalone recovery in California.

\section{References Cited}

Boolootian, R.A., Farmanfarmaian, A., and Giese, A.C., 1962, On the reproductive cycle and breeding habits of two western species of haliotis: The Biological Bulletin, v. 122, no. 2, p. 183-193, https://doi.org/10.2307/1539587.

California Department of Fish and Game, 2004, Annual status of the fisheries report through 2003-Report to the Fish and Game Commission as directed by the Marine Life Management Act of 1998: California Department of Fish and Game Marine Region, $182 \mathrm{p}$.

Chambers, M.D., VanBlaricom, G.R., Hauser, L., Utter, F., and Friedman, C.S., 2006, Genetic structure of black abalone (Haliotis cracherodii) populations in the California islands and central California coast-Impacts of larval dispersal and decimation from withering syndrome: Journal of Experimental Marine Biology and Ecology, v. 331, no. 2, p. 173-185, https://doi.org/10.1016/j.jembe.2005.10.016.

Department of Commerce, 2009, Endangered and threatened wildlife and plants - Endangered status for black abalone: Federal Register, v. 74, no. 9, p. 1937-1946, accessed May 17, 2018, at https://www.govinfo.gov/content/pkg/FR2009-01-14/pdf/E9-635.pdf.

Department of Commerce, 2011, Endangered and threatened wildlife and plants - Final rulemaking to designate critical habitat for black abalone (Final Rule): Federal Register, v. 76, no. 208, p. 66806-66844, accessed June 21, 2018, at https://www.govinfo.gov/content/pkg/FR-2011-10-27/pdf/ 2011-27376.pdf.

Friedman, C.S., Biggs, W., Shields, J.D., and Hedrick, R.P., 2002, Transmission of withering syndrome in black abalone, Haliotis cracherodii Leach: Journal of Shellfish Research, v. 21, p. 817-824.

Friedman, C.S., Wight, N., Crosson, L.M., VanBlaricom, G.R., and Lafferty, K.D., 2014, Reduced disease in black abalone following mass mortality-Phage therapy and natural selection: Frontiers in Microbiology, v. 5, 78 p., https://doi.org/10.3389/fmicb.2014.00078. 
Hastie, T.J., and Pregibon, D., 1992, Generalized linear models, chap. 6 in Chambers, J.M., and Hastie, T.J., eds., Statistical models in S: Pacific Grove, California, Wadsworth \& Brooks/Cole, p. 195-248.

Kenner, M.C., 2020, Black abalone surveys at Naval Base Ventura County, San Nicolas Island, California-2019, annual report: U.S. Geological Survey Open-File Report 2020-1047, 41 p., https://doi.org/10.3133/ofr20201047.

Lafferty, K.D., and Kuris, A.M., 1993, Mass mortality of abalone Haliotis cracherodii on the California Channel Islands - Tests of epidemiological hypotheses: Marine Ecology Progress Series, v. 96, p. 239-248, https://doi.org/10.3354/meps096239.

Leighton, D., and Boolootian, R.A., 1963, Diet and growth in the black abalone, Haliotis cracerodii: Ecology, v. 44, no. 2, p. 227-238, https://doi.org/10.2307/1932170.

Miner, C.M., Altstatt, J.M., Raimondi, P.T., and Minchinton, T.E., 2006, Recruitment failure and shifts in community structure following mass mortality limit recovery prospects of black abalone: Marine Ecology Progress Series, v. 327, p. 107-117, https://doi.org/10.3354/meps327107.

Morris, R.H., Abbott, D.P., and Haderlie, E.C., 1980, Intertidal invertebrates of California: Stanford, California, Stanford University Press.

National Marine Fisheries Service, 2020, Final Endangered Species Act recovery plan for black abalone (Haliotis cracherodii): Long Beach, Calif., National Marine Fisheries Service, West Coast Region, Protected Resources Division, 93 p., https://www.fisheries.noaa.gov/species/ black-abalone\#conservation-management.

Neuman, M., Tissot, B., and Vanblaricom, G., 2010, Overall status and threats assessment of black abalone (Haliotis Cracherodii Leach, 1814) populations in California: Journal of Shellfish Research, v. 29, no. 3, p. 577-586, https://doi.org/10.2983/035.029.0305.

R Core Team, 2017, R-A language and environment for statistical computing: Vienna, Austria, R Foundation for Statistical Computing, https://www.r-project.org/.

Raimondi, P.T., Wilson, C.M., Ambrose, R.F., Engle, J.M., and Minchinton, T.E., 2002, Continued declines of black abalone along the coast of California-Are mass mortalities related to El Niño events?: Marine Ecology Progress Series, v. 242, p. 143-152, https://doi.org/10.3354/meps242143.
Rathbun, G.B., Hatfield, B.B., and Murphey, T.G., 2000, Status of translocated sea otters at San Nicolas Island, California: The Southwestern Naturalist, v. 45, no. 3, p. 322-328, https://doi.org/10.2307/3672835.

Rick, T.C., Vellanoweth, R.L., Erlandson, J.M., and Kennett, D.J., 2002, On the antiquity of the single-piece shell fishhook-AMS radiocarbon evidence from the Southern California Coast: Journal of Archaeological Science, v. 29, no. 9, p. 933-942, https://doi.org/10.1006/jasc.2001.0788.

U.S. Navy, 2015, Integrated natural resources management plan for Naval Base Ventura County, San Nicolas Island, California_December 2010 [updated December 2015]: San Diego, Calif., Naval Base Ventura County, San Nicolas Island, Environmental Division and Naval Facilities Engineering Command, Southwest, 1760 p.

VanBlaricom, G.R., 1993, Dynamics and distribution of black abalone populations at San Nicolas Island-Third California Islands Symposium-Recent advances in research on the California Islands: Santa Barbara, Calif., Santa Barbara Museum of Natural History, p. 323-334.

VanBlaricom, G.R., and Kenner, M.C., 2020, Dietary patterns in black abalone Haliotis cracherodii Leach, 1814 as indicated by observation of drift algal and seagrass capture at San Nicolas Island, California, USA, 1982 to 2019: Journal of Shellfish Research, v. 39, no. 1, p. 113-124, https://doi.org/10.2983/035.039.0111.

VanBlaricom, G.R., Ruediger, J.L., Friedman, C.S., Woodard, D.D., and Hedrick, R.P., 1993, Discovery of withering syndrome among black abalone Haliotis cracherodii Leach, 1814, populations at San Nicolas Island, California: Journal of Shellfish Research, v. 12, p. 185-188.

VanBlaricom, G.R., Neuman, M., Butler, J., DeVogelaere, A., Gustafson, R.R., Mobley, C., Richards, D., Rumsey, S., and Taylor, B.L., 2009, Status review report for black abalone: Long Beach, Calif., National Marine Fisheries Service Southwest Region, $135 \mathrm{p}$.

Watson, J., 2000, The effects of sea otters (Enhydra lutris) on abalone (Haliotis spp.) populations, in Campbell, A., ed., Workshop on rebuilding abalone stocks in British Columbia: Canadian Special Publication of Fisheries and Aquatic Sciences, v. 130, p. 123-132.

Webber, H.H., and Giese, A.C., 1969, Reproductive cycle and gametogenesis in the black abalone Haliotis cracheroidii (Gastropoda-Prosobranchiata): Marine Biology, v. 4, no. 2, p. 152-159, https://doi.org/10.1007/BF00347041.

Wood, S.N., 2017, Generalized additive models-An introduction with R ( 2 d ed.): London, UK, Chapman and Hall/CRC, 496 p., https://doi.org/10.1201/9781315370279. 

For more information concerning the research in this report, contact the

Director, Western Ecological Research Center

U.S. Geological Survey

3020 State University Drive East

Sacramento, California 95819

https://www.usgs.gov/centers/werc

Publishing support provided by the U.S. Geological Survey

Science Publishing Network, Sacramento Publishing Service Center 
